\title{
IMAGINATION AND EXPERIENCE
}

\author{
DOMINIC PAUL MURPHY
}

M.PHIL

DEPARTMENT OF PHILOSOPHY

UNIVERSITY COLLEGE LONDON 
ProQuest Number: 10016787

All rights reserved

INFORMATION TO ALL USERS

The quality of this reproduction is dependent upon the quality of the copy submitted.

In the unlikely event that the author did not send a complete manuscript and there are missing pages, these will be noted. Also, if material had to be removed, a note will indicate the deletion.

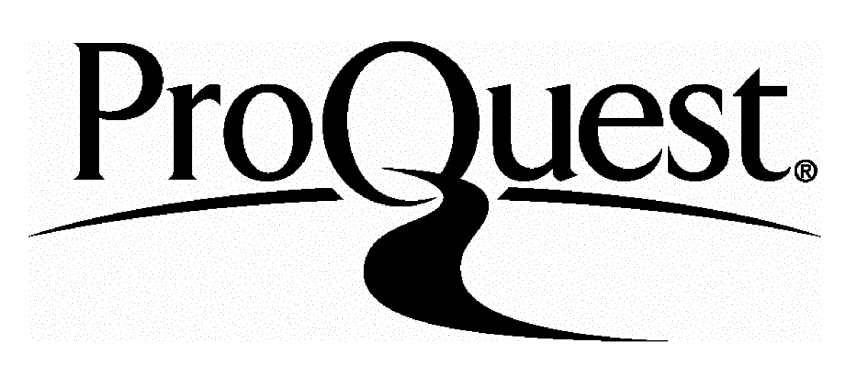

ProQuest 10016787

Published by ProQuest LLC(2016). Copyright of the Dissertation is held by the Author.

All rights reserved.

This work is protected against unauthorized copying under Title 17, United States Code. Microform Edition $\odot$ ProQuest LLC.

\author{
ProQuest LLC \\ 789 East Eisenhower Parkway \\ P.O. Box 1346 \\ Ann Arbor, MI 48106-1346
}




\section{ABSTRACT}

This thesis is concerned with the nature of the connection between perceptual experience and states of experiential imagination, the latter being states which bear an intuitive phenomenal resemblance to perceptual states. The thesis states that experiential imagination, like perception, represents the external world as being some way.

The area of imagination which is at issue is circumscribed. After this, the nature of the link between imagination and experience is examined. I turn to those features of experiential imagination which appear to make it a blend of thought and sensation. Purported criteria marking these two aspects of experiential imagination are examined. One of the purported criteria of thoughthood is intentionality, and the thesis draws a distinction between an imaginative state's being "of" something, and its being "as of" something. It is claimed that the latter involves both a sensory core and a descriptive "label" which fixes the singular content of a given type-image. Understanding the link between imagination and experience is a matter of correctly understanding this sensory core. A substantive position on this issue is developed on the basis of Peacocke's work; this position is criticised as making experiential imagination a matter of imagining a state of mind. Another approach sees the instantiation of sensory qualities as that which makes imagination experiential; this too is rejected as threatening to collapse the distinction between experience and imagination altogether. It is finally suggested that a fruitful approach to locating the relevant phenomenal similarity would seek it at the level of nonconceptual content. 


\section{CONTENTS}

1. Introduction.$\ldots \ldots \ldots \ldots \ldots \ldots \ldots$

2. The Elements Of Experiential Imagining $\ldots \ldots \ldots . .9$

3. Thought And Sensation ................ 19

4. The "Of/As Of" Distinction . . . . . . . . . . 35

5. Peacocke on "As Of" ............. 51

6. Mellor's View . . . . . . . . . . . . 70

7. Towards A Positive Account ........... 78

8. Conclusions . . . . . . . . . . . . . . .85

Bibliography . . . . . . . . . . . . . . .87 


\section{INTRODUCTION}

\section{The Concerns E Conclusions Of The Thesis}

This thesis is concerned with one particular exercise of the imagination. I shall call this type of imagination experiential or (sometimes) sensory imagination. I use these terms to try to convey the sorts of states $I$ have in mind. Whilst it is undoubtedly possible to imagine without the use of imagery, it does seem to us that there is something fundamental about the relation between imagery and what we understand the imagination to be. If you were to ask somebody to do some imagining, or ask her what is distinctive about imagining, she would as like as not use or mention mental imagery in her response. What makes these states special, and perhaps especially treasured too, is the phenomenological connection they seem to have with experience. I want in this thesis both to look at the states themselves, and to try to fathom this apparent but elusive connection with veridical perception - the experience of the world as it actually is on which experiential imagination seems somehow to be parasitic.

The thesis claims that experiential imagination represents the world as being some way; it is experiential in virtue of the way in which this representing is done. I claim that the content of such a state must be given by representational properties which the state has in common with perception,and that the best approach to the problem sees these properties as obtaining at the level of non-conceptual content. Experiential imagination is thus a state which shares representational properties with experience, and it is this, rather than any common sensational properties, which gives it its peculiarly sensory character. This character is not due to the sensational properties which some philosophers have claimed to detect in perception (e.g. Peacocke, Sense and Content, ch.1). Whether or not these sensational properties occur in 
perception, they are not shared by perception and imagination, and do not account for the relation between experience and experiential imagination. The issue is what this link between experience and the sensory aspects of imagining comes to. In particular it should be decided whether, in order to explain the sensory aspects of states of experiential imagination, one should regard them as exemplifying properties which perception also possesses.

As well as trying to figure out the connection with experience which experiential imagination has, it is also interesting to analyse these states in themselves. As well as their phenomenal properties, they also require descriptive labels. Labels are propositional contents which specify, for each token of a type-image, the singular content represented by that image. This is in large part a function of the imaginative project in which that episode occurs. The imaginer's project decides what the singular content is, and the label mentions this content. (These terms should become clear later.)

The account of sensory imagination which I shall advance sees it as partly sensation, and partly thought. This is in the spirit of much of the recent literature on this subject, and, I shall maintain, with common sense as well. However, the specifics of the current treatments often seem to me to be faulty, and in the thesis I discuss some of these treatments and indicate where dissent seems justifiable. I also try to provide an explanation of the connection between imagination and experience. It seems to me that the intuitive understanding of experiential imagination is that it is a way of imagining the world, and that philosophical arguments ought always to respect this. So I try to respect it in what follows, and venture to take issue with philosophers who flout it.

Before giving some indication of the way the thesis develops, in order to make it easier to follow, I should enter some caveats. I am not offering a general account of the imagination. What I have to say concerns experiential imagination alone. A fuller definition of it is offered in the next chapter. 
Further, I am concerned only with what Tye (in The Imagery Debate) calls the "phenomenal image"; I am going after a particular type of experience. Nothing that I have to say is directly concerned with issues concerning vehicles of content, over which cognitive scientists have spilt much ink; I shall not, for instance, look at the question of whether images ought to be regarded as analog or digital representations. (For a introduction to these issues, see the papers in N. Block (ed) Imagery. Tye (op. cit.) includes interesting discussions of the main experiments, and some original proposals.)

\section{Development of the Thesis}

The thesis unfolds as follows. Chapter 2 circumscribes the area with which the thesis is concerned and distinguishes experiential imagination from other sorts of imagination. It also attempts to supply a working definition, introducing in the course of that attempt some terms which will be explained more fully later on. In this chapter I also try to isolate the main elements of experiential imagining for further investigation. The chapter concludes by asserting that experiential imagination is a blend of thought and experience. This assertion is looked at in more detail in chapter 3. Scruton's defence of this position is examined (Scruton, Art and Imagination, ch. VII \& VIII), and some of his arguments endorsed with some qualification; it is argued that some of his conclusions support a view of imagination as exclusively sensory, and that the issue turns, in particular, on explaining the intentionality of imagery. Chapter 4 develops the treatment of intentionality, introducing the distinction between what imagination is "of", and what it's "as of". The later, I opine, involves both a sensory core and a propositional label. It is further claimed that the question of the experience/imagination link is best addressed by an attempt to understand the sensory core. Chapter 5 examines a positive proposal, Peacocke's, about how the sensory core should be understood (Peacocke, "Imagination, Experience and Possibility", in Foster \& Robinson (eds) Essays On Berkeley, pp.19-35). This is examined, and a substantive proposal is constructed from it, which is then rejected. I claim that, among 
other problems, it is too remote from how our concept of the imagination functions. Chapter 6 looks at a rival proposal advanced by Mellor ("Nothing Like Experience". Proceedings of The Aristotelian Society, vol. XCIII, (1993) pp.1-16) I conclude that Mellor's account threatens to render experience and experiential imagination indistinguishable. However, I suggest in Chapter 7 that Mellor, rather than Peacocke, represents the more fruitful general approach. I try to show that sensations cannot be instantiated in experiential imagination, and hence do not provide the link with perception. I end with some fairly tentative proposals about what the link might be. 


\section{THE CHARACTERISTICS OF EXPERIENTIAL IMAGINING}

In chapter 2 the kind of imagination which is at issue in the thesis is elaborated and distinguished from other imaginative activities. I shall be concerned only with the area circumscribed in this section, and do not pretend to offer a general account of the imagination which covers any of its other manifestations. The thesis is concerned only with experiential imagination, a state which it is easier to grasp intuitively than characterise precisely. I aim initially to build on these intuitions, so I begin by trying to sketch such an intuitive account, and show how it covers only a fraction of all imaginative states. This much I take to be in accord with our common-sense understanding of the imagination. I then go on to provide an initial definition.

The Common-Sense Understanding of Experiential Imagination

As a first rough approximation, then, one can say that experiential imagination involves the entertaining of mental imagery. I mean this in a strong sense; a daydream which includes only a fleeting episode of imagery as part of a longer imaginative episode is not experiential throughout; only those episodes which include an occurrent image are experiential. Experiential imagining is thus as of the instantiation of experiential properties. However, the use of "experiential" does not place constraints on the images which may feature in such states over and above our nonphilosophical understanding of them. Specifically, the use of "experiential" should not be taken to imply a causal constraint which holds that states only count as states of experiential imagination if they involve images the contents of which are restricted to states of affairs which the imaginer has experienced or could experience in the way that they are imagined. That is not the point of using "experiential" or "sensory" in the specification of the relevant type of state. Rather, I use "mental 
imagery" to cover what is intended to be a broad class of common-sense cases, cases which it would seem natural to us to think of as like experience in some way. The nature of the connection between such states and veridical experience is not yet under consideration; at the moment the aim is only to spell out the sort of imagining which common-sense would think of as experiential, and to indicate that whatever the link is between experience and this sort of imagination, it is not a link which, intuitively, requires us to think of only some occasions of imaging as experiential imagining.

Experiential imagination thus includes not just iconic representations of things which are possible objects of experience, such as a mental image of the Guinness Brewery, but also images of things which seem implausible candidates for being experienced, such as a blue triangle or a purple cow. Neither of these, considered as things which exhaust a given content, seem to be possible objects of experience. Triangles, whether blue or any other colour, do not crop up in our experience other than as elements of some fuller scene, such as a blue triangle on a rugby shirt or on the surface of a painting. Purple cows are also not encountered in experience, cows not being purple beasts. But the fact that these images answer to no single objects of experience is no bar to those objects being experientially imagined. The images of experiential imagination need not be scenes; the link with experience is not such as to make an image equivalent to a complete visual field. (I ignore the complication that one might think a blue triangle a possible singular content if, for example, it was a patch on some surface, and one was so close to that surface as to be experiencing the patch and nothing else.)

The link with experience is also not such as to make an image as determinate, in every respect, as a perceptual experience can be. When one images, not every aspect of the image is determinate. This does not mean that what is imagined is specifically imagined as indeterminate with respect to the possession of any property or set of properties. Although this can be done, it is commoner to imagine something as possessing a given property, but to an 
indeterminate degree. Suppose one believes that every actual tiger has a determinate number of stripes. Since this is one's belief, one images a tiger as striped, and imagines it to have a determinate number of stripes. Still, there is not any one determinate number of stripes that one thereby imagines one's mental tiger as having. (For a full discussion of this couched in terms of the qualitative richness of imagined possible worlds, see S. Yablo, "Is Conceivability A Guide To Possibility ?", Philosophy and Phenomenological Research, March 1993, pp.1-43) Commoner still is the simple omission of imagining a property. One can image a house without imagining it as having any number of chimneys, but in doing this one is not imagining that it is without chimneys. It is just that one is not specifying anything with regard to chimneys when one imagines the house, just as one could describe a house without saying anything about chimneys.

A third point about mental images ought to be made here. Following much precedent, I shall include within the extension of "mental image" such phenomena as imagining a tune, or a taste or smell, and so on; "image" should not be construed as purely visual. When the ensuing discussion uses examples, they will mostly be drawn from visual imagery, but the account takes "images" in this wider sense as its explananda.

Lastly, images need not be voluntary. Voluntariness is often thought of as an essential to imagination, but this is false. No part of our everyday understanding of imagination requires that every imaginative act be a deliberate voluntary act on the part of some subject. Indeed, it seems clear that we should not wish to exclude unbidden images, or images that are persistent, but unwanted. These count as instances of experiential imagination, just as sudden involuntary flashes of insight or inspiration belong to imagination in the wider sense. It is part of our understanding of imagination that it is often a deliberate and voluntary activity, but it is not part of our understanding of imagination that every single exercise of it be deliberate. However, such things as after-images and hallucinations do not count as imaginings. Their sensory 
nature alone does not make them aspects of the imagination, and the fact that they are involuntary does not establish their kinship with involuntary episodes of sensory imagining. It seems likely that we understand such episodes as the occurrence of after-images to have a particular causal history which imaginative episodes ought not to have, and there is more to this causal history than mere involuntariness. I propose, then, to bracket after-images off as a special case. Similar considerations mean that dreams will not here be treated as exercises of the imagination. Dreams are not under our conscious control; not only their onset but also their development are entirely beyond our apparent powers of influence. A subject can influence her own daydreams, however, and since a daydream can involve imagery, such reveries can be, or include, states of experiential imagination.

I take it that these elements are all part of what the everyday understanding of experiential imagination amounts to. Before going on to sharpen up the account, however, I want briefly to clarify the precise extent of that portion of imagining with which I am going to be concerned. This should help to bring into focus the methodological constraints imposed on what is forthcoming.

\section{The Extent of Experiential Imagination}

It should be clear that an examination of experiential imagination is not on that basis alone an investigation of the imagination as a whole. There are many episodes of imagining which do not involve any imagery at all; this should be uncontroversial, since there is clearly no valid inference from "S imagines $\mathrm{X}$ " to "S entertains a mental image of X". What may be disputed, however, is my further contention that we have no reason, before beginning an investigation of imagining, to suppose that there is a common operation of the mind covered by all the different applications of the protean term "imagine" and its cognates. In particular, there is no need to assume that mental imagery, in some sense, is what confers a unity on these various operations. 
The assumption that the existence of a common imaginative operation need not be taken for granted a priori could be disputed, and indeed has been by, for example, Mary Warnock (in her Imagination). Warnock thinks not only that there is a common imaginative operation, but that imagery is central to it; her book is an attempt to "trace a single thread which runs through different accounts of imagination, and different instances of its exercise" (ibid. p.9) . This thread is seen as the connection between "our commonplace perceptual experiences" and "our most outlandish interpretations", a connection which "can only come by way of the concept of imagination as that which creates mental images, perhaps the most ordinary sense of the word "imagination" that there is" (p.10). (In fairness to Warnock it is worth pointing out that although she introduces the assumption, it seems to me, by fiat, she does go on to offer reasons for it. I shall not discuss these reasons here.) It is far from clear, however, that the most ordinary ways we have of talking about imagination do in fact bear any form of commitment to imagery, or to a view of the imagination as the creator of imagery. The defence of the procedure adopted here, of treating experiential imagination as a distinct focus of explanation, is that firstly, the fact that some imaginative states are experiential and some are not make it unlikely, on the face of it, it that imagery is the primitive imaginative phenomenon, and secondly that if imagery were the primitive imaginative phenomenon an examination of experiential imagination would not necessarily say that it was not, since in that case the examination would be of one particular product of that primitive operation.

Intuitively, the area of concern is only those states that are talked of using language which adverts to images. It seems that the imaginative vocabulary can be divided up into the imagistic and the non-imagistic, and this thesis is concerned only with the former. For this to be legitimate as a starting-point it ought to be the case that non-imagistic language carries no hidden commitment to imagery, and this does in fact seem to be the case. There are obviously some ambiguous uses; Strawson cites the case of 
Wellington at Salamanca, observing the French manouevre injudiciously and in that moment visualising that the day was his. (P.F Strawson, "Imagination \& Perception", in Foster \& Swanson (edd) Experience and Theory, pp.31-53, at p.50) Such cases are not troublesome; despite the unclarity as to whether, in Strawson's example, one is, or is not, saying of the Iron Duke that he enjoys a mental image of the French in flight, one need not generalise from such cases to the claim that the imaginative vocabulary is thoroughly iconophilic. Only if this widespread commitment to imagery did obtain in talk about imagination would Warnock's assumption be supported, and mine undermined. Since this is not so, the fact that ordinary language implies no identification of imagination with distinctively experiential imagination means that there is no reason as yet to object to my failing to aspire to a general treatment of the imagination, nor to any absence of claims about the wider context of imagination.

\section{A Definition Of Experiential Imagination}

The philosophical literature on imagination has always been most concerned with mental imagery, or what I have been calling experiential imagination. The tradition used to see such cases as instances of the summoning up of copies of perceptual impressions from that part of the mind responsible for their safekeeping, much as television news companies run library pictures to illustrate current stories. This is a rather inaccurate stereotype of traditional empiricism, but, perhaps because of its easy intuitive appeal, it was a view which lingered on to at least William James. James began his treatment of the imagination by claiming that sensations, "once experienced, modify the nervous organism, so that copies of them arise once again in the mind after the original outward stimulus is gone. No mental copy, however, can arise in the mind, of any kind of sensation which has never been directly excited from without." (The Principles of Psychology, p.690. Although historically inclined investigators of imagination often take the empiricists as 
their starting-point, the idea, common to Hume and Kant, that imagination plays a role in perception, dates from the Greeks; see G. Watson, Phantasia in Classical Thought, for an excellent account of the development of the concept of imagination in Ancient \& Mediaeval Philosophy).

What I am interested in in this chapter is the correct analysis of the elements of experiential imagination, and the light this sheds on the link between such states and episodes of veridical perception. An adherent of the copy picture is likely to be led to conclusions on these issues by the requirements of the wider theory. For at least the time being, however, I shall approach the matter the other way round. To begin with, I shall concentrate on trying to work out what the elements of an episode of a state of experiential imagination might be. Only after this will I try to connect the position arrived at in this regard with perception.

It is a commonplace that imagination allows us to think about nonactual things, about absent actualities, and to transform, in thought, even those things which are near at hand. In all these cases it seems that something is being thought of as being some way; the possible as actual, the absent as present, the factual as fictional. This last case is perhaps the most common; one may think of somebody, say John Major, as being taller, or as having long dark hair and a taste for tartan suits. In this sense, there is a similarity between imagined states of affairs and possible worlds; in both cases we may think of some actual object transformed so as to render true of it certain predicates which are not actually true of it, whilst at the same time excluding or being silent about the application to it of other predicates which it actually satisfies. This formal connection between possible worlds and imagined scenes has been exploited by some philosophers, who talk of the world that is imagined by the subject; most explicitly by Yablo (op. cit.), although Christopher Peacocke has used a similar device ("Imagination, Experience and Possibility", p.19) In both philosophers mental imagery is involved in imagining the imagined world, but clearly this is not essential to the construction of a possible world any more 
than it is in the general case of imagining. The use of mental imagery does seem quite unobjectionable in giving an account of what can go on when one imagines a world, however; this suggests that one may regard imagination which does involve imagery as continuous with other sorts of imagining. Experiential imagination is one way among others of thinking of something as other than it is; Scruton (Art \& Imagination, p.90) calls this "thinking of $X$ as $Y "$ ".

It is not in thinking of $X$ that the sensory properties of an episode of experiential imagination come in, however; it is more plausible to suppose them to constitute a particular way of thinking of $X$, and thus as falling under the "as $Y$ ". One may think of John Major as hirsute without entertaining any imagery, but it seems clear that entertaining images is one way of thinking of John Major as hirsute. What seems special about the latter case is its apparent similarity to a perceptual experience which represents John Major as hirsute. This is an experience which could obtain in more than one modality. Although the obvious way in which one would perceive that John Major is hirsute is by seeing him, one could equally well stroke his silken tresses in a darkened room, and one could imagine doing this too.

If, in imagination, one thinks of $X$ as $Y$, then there is an immediate candidate for the connection of imagination and experience, which is that according to the most popular current theories of perception, perception is intentional, representing the world as being some way. (For intentional theories of perception, see e.g, D. M. Armstrong, A Materialist Theory of the Mind, ch. 10; F. Dretske, Knowledge and the Flow of Information, ch. 6; C. Peacocke, Sense and Content, ch.1; G. Pitcher, $A$ Theory of Perception,; J. Searle, Intentionality, ch.2.) Thought represents the world as being some way, and so too perception, just as in imagination one thinks of $X$ as $Y$ either with or without images. I shall assume a representational theory of perception in what follows, and try to establish a connection on that basis, but it is worth pointing out here something I will go into more detail about later on. The connection 
could be thought of in two ways. One could think that in experiential imagination one represents the world some way, and look for the sensory properties of the state which do the actual representing. On the other hand, one could argue that in experiential imagination one imagines a representational experience. Peacocke (in "Imagination, Experience, and Possibility") takes the latter course; this makes all episodes of experiential imagination into imaginings of a state of mind, and seems to me intuitively implausible for that reason. I shall go into this in much more detail in chapter five; for the moment I shall try to remain agnostic between these two approaches.

The search for the elements of sensory imagination which could be built into a definition has reached this stage; like imagination generally, experiential imagination is the representing of $X$ as $Y$ (for the time being, I shall use this locution to cover Peacocke's interpretation also). The distinctively sensory properties of a state of experiential imagination are the properties in virtue of which such a state does the representing of $X$ as $Y$. There is an immediate problem however, which is that an image alone cannot represent a particular without some accompanying propositional content. I shall expand on this in chapter four, but the basic point is simple. Suppose one entertains an image of John with a bulging stomach; the image will equally well represent John as fat or represent John as pregnant. There will also be numerous properties which the image represents John as having which will be irrelevant to what is being imagined about John. Without some sort of descriptive "label" there is no way of deciding what is represented, and a consequent problem in seeing how the image could be used to further an imaginative project. (The example comes from J. Fodor, The Language of Thought, pp.180-81. The first point, about images picking out something in too many worlds, derives very much from the later Wittgenstein).

There is thus a clear need for an accompanying label, just as a picture, which has the same ambiguity problems as an image, needs a title to let its 
audience know what it's about. Peirce was thus wrong to claim that an icon was a "sign which refers to the object that it denotes merely by virtue of characters of its own" (C. S. Peirce, "Logic As Semiotic; The Theory Of Signs", in Philosophical Writings of Peirce, ed. Buchler, p.102). Images are types, and need a label to interpret them.

The accompanying descriptive label which interprets an image derives from the imaginative project in which the image occurs. Typically, one imagines for a purpose, and so uses the image towards that purpose. Walton develops this insight to ground a conception of imagination as rule-governed, the rules being put in place by the imaginer. (K. Walton, Mimesis As Make-Believe, ch.1) I shall use the term "imaginative project" to denote such a rule-governed occasion of imagining. Not all imagining fits this picture, obviously, but on those occasions in which images or other imaginative thoughts arise unbidden it seems that we may choose to use them in an imaginative project, and thus develop a set of rules to cover them. (Walton extends his basic account in this fashion (see p.44).) We are, as it were, thrown the ball, and we can then decide which game to play with it.

Now, it is clear that a project need not always employ images. One may embark upon a daydream, and after a while introduce images, and different images may succeed one another. I shall use the term "imaginative episode" to denote each of the successive parts of an imaginative project; even in a project which employs imagery, it is not necessary that all the episodes be partly constituted by an image and its accompanying label.

\section{A Tentative Definition, And Its Consequences}

The elements of experiential imagination have begun to take shape; in imagining, one thinks of $X$ as $Y$. In experiential imagination, the way one thinks of $X$ as being is constituted partly by the sensory properties of the image. The image is a type-image however, the relevant singular content being 
fixed by the descriptive label which accompanies it. This description, along with the image, constitutes the sensory part of an episode of experiential imagining which occurs in an imaginative project. So as a first, tentative, definition to proceed with, experiential imagination can be defined as imagination in which an object is represented as being some way in virtue of the sensory properties had/an imaginative episode. (There are a lot of terms in this last paragraph which have yet to be fully explained; I hope that at least the bones are clear at this stage. The succeeding chapters will put some flesh on them.)

There are some points worth making about this definition, and the more general framework of the elements of experiential imagining which suggested it. One is that the order of explanation which Warnock took to be mandated by the commonsense understanding of imagination has been inverted. Rather than seeing imagination as a "power in the mind" (Warnock, op. cit. p.196) to be explained in terms of mental imagery, this account uses a general approach to imagination and regards experiential imagery as a special case of a more general phenomenon covered by that wider account.

Furthermore, the account sketched thus far attributes to experiential imagining aspects deriving from both thought and sensation. This I take to be in agreement with commonsense, but it needs further examination to spell out what these different aspects amount to. I begin this examination in the next chapter of the thesis. I look first at the work of Scruton, who has argued for the view that imagination is a blend of thought and experience; he will be a convenient stalking-horse in the attempt to see how far this picture of experiential imagination is justified. 


\section{THOUGHT AND SENSATION}

In the last chapter the discussion of the common-sense view of experiential imagination and its philosophical treatments suggested that experiential imagination is a blend of thought and sensation. A natural way to think of it would be as having both propositional and sensory aspects. It will be convenient, then, to consider a philosophical theory of the imagination which endorses and argues for this picture and may serve as a route into the issue, to see if it provides some clues as to how this understanding of experiential imagination might be fleshed out.

A philosopher who has claimed that imagination involving the use of imagery is a blend of both thought and sensation is Roger Scruton (in chapters VII \& VIII of his Art \& Imagination). Scruton offers a general characterisation of imagination, as well as a more specific treatment of sensory imagination, including a specification of what he takes to be the features of experiential imagination which it shares with thought and the features which it shares with sensation. I propose to discuss Scruton's views to see how far his arguments are succesful in establishing that experiential imagination has this schizoid character.

\section{Scruton's View Of Imagination - General Remarks}

Scruton understands imagination in the broadest sense to be a rational activity involving the entertainment of unasserted thoughts; certain states of mind, such as amusement or horror, are appropriate responses to imaginary, as well as real, states of affairs. In such situations the response is not based upon a judgement or belief, and so imagination is not a form of belief, and the declarative sentences which are entertained in imagination are not ones which express beliefs; that is, they are not assertions. Imagination, says Scruton, is an activity "essentially contrasted with belief" (op. cit. p.76). To speak of an 
"essential contrast" is to make quite a strong claim, and one which is not immediately seductive, since, as Walton points out, "imagining something is entirely compatible with knowing it to be true" (Mimesis as Make-Believe, p.13). Walton puts the same basic point more weakly; imagination is independent of belief (loc. cit).

Involved in imagination, argues Scruton, is a mental act of entertaining, unasserted, the proposition that $p$; this is analogous to uttering the same proposition without assertoric force, in the same way as judging that $p$ is analogous to overtly asserting it. (see M. Dummett, Frege; Philosophy of Language, p.298) This entertaining of propositions is regarded by Scruton as a rational activity; not the rationality of belief, but a species of practical reason; "propositions are entertained for a reason, and the reason is to be found in the subject matter and nowhere else" (op. cit p.99). The imaginer tries to come up with a story that is designed to further the imaginative project - the plausibility or truth of the story or its elements is neither here nor there.

Rational unasserted thought is thus present in imagination, and it seems that we must look in this area for the aspects of experiential imagination which are shared with thought; Scruton contends that four such marks of thoughthood are properties of experiential imagination. I shall assess this contention shortly. He also offers two characteristic features of imagery which make it like sensation; exact duration and intensity. I shall consider these first, and then go on to the four alleged marks of thoughthood.

The idea that sensations, images and like "states of consciousness" or "undergoings" possess a genuine duration which marks them off from dispositions such as emotions, beliefs or knowledge is familiar from Wittgenstein. (see e.g Remarks on the Philosophy of Psychology, vol. 2, \#45, 63). The idea is that sensations possess a genuine exact duration which could be timed; if circumstances were right, the onset and departure of a sensation could be accompanied by the switching on and off of a stopwatch, for 
example. However, even if one accepts this, there might still seem to be a plausible argument to the effect that occurrent thoughts, such as the judging that $p$, might also be measurable in this way. (Especially, perhaps, if $p$ is an extremely long sentence.) It seems at least arguable that occurrent thoughts might have the feature of exact duration, too (the "possibility of their being synchronised, of simultaneous occurrence" as Wittgenstein puts it at op. cit \#63). However, even if the assertion that exact duration marks off sensation from thought is disputed, it seems that intensity or vivacity as a feature of thought is hard to make a case for; as Scruton stresses, intensity in this context has nothing to do with degrees of belief. Images can fade, or be more or less forceful, just as sensations can run the gamut from being barely noticeable to being barely endurable. Thoughts can be entertained with more or less conviction, but they do not exhibit intensity in this sense. (Although they can be accompanied by an intense sensation.) This certainly seems to identify a property common to both sensation and imagery, regardless of the force of the point about duration. I turn now to the four reasons Scruton gives for regarding imagery as not just sensation, but sensation blended with thought.

\section{Scruton's Four Reasons}

Scruton thinks that imagery is a blend of thought and sensation. To support this contention, he argues that imagery shares four properties with thought, and that these confirm his view that imagery is a type of thought, albeit one with sensational properties, since they provide "strong reasons for saying that an image is a kind of thought of something - my image of my mother is my thought of her as she looks (op. cit. p.100-101). In this section I look at at Scruton's four purported criteria of thoughthood that are shared by images. I conclude that two of Scruton's four criteria are consistent with any wholly sensational view of experiential imagination, and that the other two require more defence than Scruton gives if his claim is to be accepted.

The first of Scruton's criteria which is clearly consistent with a purely sensational view of experiential imagination is that we have incorrigible 
knowledge of our image contents as we do of our thoughts; "imagery, like thought, is an object of immediate knowledge. I know immediately, on no basis and incorrigibly, the nature of my own images and thoughts" (p.100). The second criterion which Scruton gives which is consistent with images being sensations is that images and thoughts meet similar third-person criteria of identity and ascription; "images and thoughts are identified in a similar way, and ascribed on a similar basis" (p.101)

The third and fourth criteria only succeed in establishing that experiential imagination is a blend of thought and sensation if they are supplemented by further arguments which Scruton does not provide. The third criterion is that imagery is as voluntary an activity as thought; "imagery is subject to the will, in the same way that thought is subject to the will" (p.101). The fourth and last criterion is that images, like thoughts, have intentionality; "an image is always an image of something - imagery has the intentionality characteristic of thought, and this is brought out by the fact that one can only imagine what one can also think of" (p.100). I begin by eliminating the first two criteria, which I claim cannot serve as Scruton wishes them to. I then indicate how the latter two might be supplemented to establish something like Scruton's claim.

\section{Incorrigibility}

Ibegin with Scruton's argument from incorrigibility (which is dealt with secondly in his discussion); Scruton accepts that one can revise an interpretation of an image after it has been imaged, but this is not the sense in which he employs incorrigibility. Rather, he rejects the suspicion that one can suppose one's images to have non-relational properties which they do not in fact possess (p.100n). I do not dispute this claim, but I cannot see how Scruton can use it to support his argument that its truth indicates a ground for distinguishing imagery from sensation. There are two problems; the incorrigibility thesis lets into the realm of thought kinds of images which Scruton wishes to exclude, and it seemingly fails to apply to thoughts alone, 
rather than to thoughts and sensations both.

Scruton asserts that his criteria, taken together, "create an immediate distinction between images and such things as dreams and after-images." (p.101) This distinction cannot be supported by an appeal to incorrigibility, since it seems that my knowledge of the non-relational properties of my after-images and dream-images can be just as incorrigible as that of my imaginative images. I can easily say that I have an after-image which seems round and red, for instance, just as I can conjure up a seemingly round and red image when imagining. In both cases I can revise my interpretation of what the image is of. I could admit that I had tried to imagine an apple but come up with something that looked more like a beach ball. Equally, I could describe the after-image, when it first occurs, as of an apple, and then revise that by reporting that really it was more reminiscent of a beach ball. If the distinction between non-relational and relational properties holds good for imagination-images then there seems no reason to deny that it holds in the case of after-images as well. In the same way, it seems implausible to deny that one can use the language which is typically used to describe the non-relational properties of imagined images to describe the non-relational properties of after-images. The distinction is made in experience because one is aware of the differences in the way different images are caused; after-images and imagination-images are experienced as caused by different events or processes. But at the bare phenomenological level, as it were, it seems obvious that after-images can have the same non-relational properties as other sorts of images, and this is reflected in the fact that the same language can be used in the different cases. I said in the last chapter that after-images, like dreams, should be bracketed as a special case; Scruton certainly distinguishes them from the relevant imaginative states. But in that case imagination is not going to be circumscribed as Scruton wants.

The same is true of dreams; it might be objected that the non-relational properties of dream-images are vague or faint or labile, but the same seems 
true of many imagination-images too, and Scruton does not regard this as sufficient grounds for denying incorrigible knowledge of them to the imaginer. It is also not open to Scruton to say that although the language used to describe images is constant across different types, the knowledge one has of them differs from case to case. Scruton thinks that images are typically ascribed on the basis of the language used to describe them; if different sorts of images are described, and hence ascribed, in the same ways, and if this linguistic similarity rests on an apparent phenomenological similarity, then the appeal to incorrigibility cannot distinguish imagination-images from images of other kinds.

It might be possible for Scruton to accept this but to argue that the distinction between different sorts of imagery is effected by other of his criteria. In this case he might claim that what the argument from incorrigibility showed was not a distinction within images but a distinction between images and thought on the one hand, and sensations on the other. This would make incorrigibility necessary but not sufficient for thoughthood. Clearly, the non-incorrigibility of sensations would have to be shown for this to work, and showing this is very difficult.

The fact that one can have incorrigible knowledge of after-images might seem alone to establish the existence of a class of sensations for which it is possible to claim incorrigible knowledge. But there are even more paradigmatic cases of sensations which are incorrigible; the sensation of pain, for instance, or a sweet taste, or the touch of velvet, are surely known just as immediately or incorrigibly as mental images are known. It is of course possible to convince somebody that what she tasted as sweet was not really sweet, but only seemed so to her because her taste-buds were affected by illness. However, this does not, on the face of it, mean that she did not experience a sensation of sweetness when she sipped her day-old bitter. That she did experience it as sweet, and that she knew incorrigibly that her experience had that quality, seems no more implausible an assertion than that 
she would know incorrigibly what she imaged when she imagined herself enjoying a favourite pint.

It might be, though, that one might claim that there are sensations which are not known incorrigibly, and thus that the argument from incorrigibility does establish a principled difference between images and sensations. One way to do this would be to deny that one does have incorrigible knowledge of after-images and other sensations, whereas one does have such knowledge of images. The way philosophers normally go about showing this is by appeal to cases in which one "sees stars", or, in the writings of those sympathetic to sense-data, cases in which one is aware of a sensedatum of, for instance, a speckled hen, but is unaware of the precise number of the speckles. (See, for a good discussion of this issue, J. Foster, A.J. Ayer, pp.172-74.) The basic contention is that in such cases one is aware of the instantiation of specimens of something, but unaware of the number of instances. This is generally taken to be a case of the failure of incorrigibility with respect to sensations.

These contentions may well be true, but again it is unclear if they can support Scruton. I said earlier (pp. 9-10) that images can be indeterminate with respect to some of their features. Since Scruton wishes to claim that images are known incorrigibly, it would be unwise of him to cite the indeterminacy of the sorts of sensations mentioned above, because images can be similarly indeterminate. One may be aware of a sensation with certain properties without being aware that it has those properties to any specific degree (see Foster, op. cit. p. 174). The same seems true for images; one may image a striped tiger and at the same time not be aware of any determinate number of stripes. One might argue that the gap between awareness-of and awarenessthat cannot exist in the case of images; there can be no more to the image than the imager puts in. This is true, but there seems little reason to suppose that the imager need be aware of all this at first glance, so to speak. It is entirely consistent with the image being wholly a creation of the imaginer that the 
imaginer may learn things about the image. In the same way, if an indeterminate sensation persisted long enough, one might be able to learn all that there was to know about its nonrelational properties.

The conclusion then is that the argument from incorrigibility does not establish a distinction between thought and sensation on the grounds that incorrigibility attaches only to knowledge of the former. It follows that it does not establish that images are a blend of thought and sensation. In fact, one might even want to argue that one can more easily be wrong about one's thoughts than about one's sensations; if imagery were always known incorrigibly then that argument would make them a species of sensation rather than a type of thought. I shall not argue for that here however; the aim here has only been to argue that Scruton's claims about incorrigibility do not establish that the relevant sorts of images have properties which are had by thought but not by sensations.

\section{Identification \& Ascription}

The nature of the criteria for identification and ascription of thoughts is the fourth item on Scruton's list and is discussed by him at greater length than any of the other three (pp.103-6). Like his claim that thoughts are known immediately and incorrigibly the claim that thoughts (and a fortiori images) are ascribed on the basis of publicly observable behaviour is true but insufficient to establish his point, because it is true of sensations as well.

It is surely correct that images, like thoughts, are ascribed and identified on the basis of reports and other behaviour of the imager. It seems, however, that the same is true of sensations. Like thoughts, they cannot be experienced or entertained by anyone other than the individual who has them, and so any third-party must ascribe them on the basis of that individual's observable behaviour. What might do the trick, however, is an obvious difference in the way in which thoughts and sensations are ascribed. If such a difference were evident, and if images were ascribed like thoughts, then some form of the 
distinction could be preserved. It is not clear that this can be done, however.

Scruton says the following about the way in which images are ascribed; "[w]hen a man refers to an image that he has, he describes it in terms of a genuine experience, the publicly observable form of which is familiar to us all; he will describe his visual image of $X$ in terms that are equally appropriate to the experience of seeing X." (p.104) This is correct, but insufficient to establish Scruton's claim as it stands. If Scruton is arguing that what happens in such a case is that the imaginer may bring it about by her behaviour that $I$ understand her experience by relating it to a kind of experience that I (or someone else ) could have, such as a perceptual experience or a mental image of my own, then his argument is sound, but of no use to him. This is because it seems that the picture Scruton gives in the cited passage of our understanding of another's experience would apply to sensations just as well as it applies to thoughts. The understanding that another is in pain, say, proceeds in just the way that Scruton claims the understanding that another is imagining proceeds; in both cases, I understand that you are X-ing by judging that your behaviour is behaviour which typically is manifested by an $\mathrm{X}$-ing subject. I can in both cases relate your experience to a similar possible experience of my own.

There is another way of reading Scruton's passage, which construes him not as explaining how we come to know that a subject is entertaining images, but how we come to know what the images the subject is entertaining are images of. Support for this construal comes from Scruton's remark that "a man might express his image by drawing or pointing to a picture" (p.101). This construal seems of no greater use in establishing a disanalogy between images and sensations, however. A bare image, such as one might draw or point to, is potentially of a number of particulars, and must be supplemented by a descriptive label, so it is unclear if a man could invariably communicate his image in this way. Even if it were possible, it is far from clear that the addition of this extra means of communicating information about one's image 
proves anything. After all, there are ways in which a subject can communicate a sensation which could not be used to communicate an image, such as sticking a red-hot poker into a listener's armpit.

Alternatively, we might consider a situation in which what is reported or pointed to is a pattern of colours and shapes, on the basis of which the hearer, as it were, figures out the object imaged. Such a case seems analogous to one in which a sensation is not reported as of something, say velvet, but rather as a bit like this, but with a hint of that; we are in no doubt that wine buffs are describing sensations when they go into paroxysms about the myriad delightful tastes to be found in a bottle of their chosen nectar.

The upshot of the discussion is then that Scruton is certainly right to assert that images are ascribed on the basis of behaviour accessible to third parties. This does not show that imagery is a form of thought, since the same thesis about the communication of one's current experience is true if that experience is a sensation; indeed, there seems no other way in which to communicate current experience, regardless of its character. (A brain-scanning device might tell one what another's experience was, but there seems no reason to suppose it would tell us about only one of sensations or images.) Like the point about incorrigibility, the point about the identification and ascription of thoughts seems to be as applicable to sensations as to thoughts, and to undermine the distinction that Scruton is trying to establish.

\section{Voluntariness}

The third criterion I come to is the voluntary nature of images; this Scruton takes to distinguish mental images from after-images, since we have no control over the latter. The supposed voluntariness of mental imagery is a venerable hallmark of the imagination, just as much as their lesser vivacity and coherence; "I find I can excite ideas in my mind at pleasure, and vary and shift the scene as oft as I think fit. It is no more than willing ... [t]his making and 
unmaking of ideas doth very properly denominate the mind active" (Berkeley, "Principles of Human Knowledge", I \#28, in Berkeley, Philosophical Works). Care is needed here, however, since it is apparent that images do not form a class all the members of which are under the control of the will; not all imagination is deliberate or voluntary, and mental images may come upon one unbidden, just as thoughts can in daydreams. Equally, images may outstay their welcome, and, having been conjured up voluntarily, they may not depart in the same manner; this is a notoriously annoying habit of auditory images such as tunes heard in one's head, or half-remembered snatches of conversation. In fact this property of imperfect subjection to the will is commmon to both images and thoughts, and although Scruton does not claim that imagery is as subject to the will as thought is (p.101) it seems that he could plausibly do so. This would support Scruton by establishing an exact parallel between images and thoughts in this regard, and tend to support his claim that imagery is a form of thought, if it could be shown that sensations are not subject to the will.

Someone unsympathetic to Scruton is likely to object here by questioning how far it is legitimate to class images and thoughts as voluntary rather than arguing that sensations are just as voluntary as images and thoughts. It seems singularly heroic to claim that sensation is ever as directly linked to the will as thought is at least some of the time. One can cause oneself to have a sensation of course, but only indirectly; one might deliberately stub one's toe, for instance, or deliberately shine a red light in one's own face. Although these are cases of bringing about sensations in oneself it is pretty clear that in these cases the link to the will is not as direct as it in the case of deliberate thought or imagination. The situation would be complicated, however, by someone who felt that there were good grounds for holding that experiential imagining did involve sensations; someone who felt compelled to this conclusion on independent grounds might be led to claim that here, in experiential imagination, one finds precisely that class of sensations which can be under the control of the will. (I will come back to this later). Leaving such 
gadflies aside for a moment, it seems much more promising to attack the view that images, like thoughts, are under the control of the will.

The natural way to mount such an attack would be to say that voluntariness cannot mark off imagery from sensations, since not all images are voluntary, and that the same type-image could as easily be under or outside the control of the will. Scruton's position is that because I can form an image on occasion, and so forming images is not simply a process that one undergoes, there is a good reason for believing in the voluntariness of images, and it is a consequence of this feature of imagery that it makes sense to order someone to form an image of something; it is possible to make a deliberate decision to obey such an order, and to do so directly, rather than, as with sensations, to merely bring it about that one undergoes a sensation by doing something else. (Scruton, op. cit. pp.95-97)

It might seem that such an account of the voluntary nature of imagery is little more than an assertion that imaging can be done intentionally. Peacocke has urged this objection against Wittgenstein's treatment of imaging, claiming that it is uninformative ( "Wittgenstein and Experience", Philosophical Quarterly, no. 32 (1982)). Many of the elements of Wittgenstein's account occur in Scruton's also; the idea that "Imagine that" is a sensible order is in Wittgenstein (Wittgenstein, Remarks On the Philosophy of Psychology, vol. I, $\# 83$ ), as is the understanding of imagining as an activity (ibid \#88, 111, 116 - although Wittgenstein does not stress the rationality of the action as much as Scruton does). If these elements make Peacocke's objection less than fully telling against Wittgenstein, they should also block the same objection to Scruton's treatment.

The key to this understanding of imagery is that it sees imaging as an activity, and that its voluntary nature is intrinsic to it; it is this voluntariness that distinguishes experiential imagination from perception. (This paragraph draws heavily on M. Budd, Wittgenstein's Philosophy of Psychology, pp.104-11) 
Precisely the wrong way to think about experiential imagination is to think of it as the occurrence of the sort of experience that occurs in perception, but with a different causal history, so that in imagination the same experience recurs, but this time driven by the will. Such an understanding makes voluntariness an extrinsic property of the visualisation, whereas the burden of Wittgenstein's account is that the voluntariness of experiential imagination is intrinsic to it; it is definitive of the kind of experience that experiential imagination is. Experiential imagination is not a type of experience which can also occur in sensation, but with the will added to it as a peculiar intentional engine. This idea of imagining as an activity is not vulnerable to the idea that images occur against one's will; someone who cannot stop visualising something is in the same state as someone who cannot get to sleep because she is unable to stop thinking about something (Budd's example, ibid. p.109). In both cases the subject is active, just as she would be if she were suffering from a compulsion to repeatedly wash her hands; that is, in these cases she is active, as she would not be if she were merely undergoing a muscle spasm. On the other hand if one thinks of the contents apt to occur in experiential imagining as equally apt to crop up in other contexts, but with a different history, then the case of persistent images will indeed seem like an objection to imaging's being a voluntary activity.

The precise characterisation of the connection between imagination and the will is important. It is not enough to say simply that imagination is subject to the will just as thought is and leave it at that, because that leaves an opening to the objector considered earlier. Such an objector will say that images are sensations, and that they just happen to be that class of images that are subject to the will in some sense. There are two possible responses to this objection; the first would be to argue that the hypothesis that images are sensations is ruled out on other grounds. However, the trouble with this is that the independent grounds which are on offer currently are incorrigibility and criteria of ascription. Neither of these will do the job. The second kind of response would spell out the link between imagination and the will in such 
a way as to rule out the possibility that images could be sensational. It seems difficult to portray the having of sensations as an activity, and so if it is true that imaging is an activity then the objection will be met.

A heroic course for the objector now would be to classify imaging as an active production of sensations. An orthodox Wittgensteinian answer is that our concept of sensation disallows this, since it does not make room for the possibility that sensations might be voluntary. The objector is likely to remain unmoved and argue that if the price of truth is some slight revision of our concept of sensation then the price should be paid. The main trouble with the heroic response is that it has a desperate air of the ad hoc about it. It is very hard to think of any other class of sensations which are thus active, for instance.

The common elements of Scruton's and Wittgenstein's views allow the defence of the former along Wittgensteinian lines. If it can be successfully bolstered in this way then voluntariness will provide a non-sensational criterion of experiential imagination. I will not pursue the question of how successful this defence might be here, however; my aim is only to indicate that it could be used to meet some objections that might be urged against Scruton's argument from voluntariness. I come now to the last of Scruton's features of imagery; intentionality.

\section{Intentionality}

The discussion has reached the following position. It has been argued that incorrigibility is at least as much a feature of sensations as of thoughts, and that both thoughts and sensations are ascribed in the same ways. Therefore, neither of these give Scruton what he wants, which is a feature had by thought, but not sensation, which is also a feature of imagery. Voluntariness, on the other hand, might do the necessary if it were spelled out along Wittgensteinian lines; it has been argued that there is sufficient kinship between Scruton and Wittgenstein on this topic for this to be done without 
excessive violence to Scruton's position.

I turn now to intentionality, which is certainly a feature of thought. As in the previous cases, it is not Scruton's attribution of the feature in question to thought or to imagery which is in dispute. Rather, it is his assumption that the feature is one which does not attach to sensations. As Scruton says, imagery is intentional in the sense of being about something - it portrays something as being a certain way. The fact that imagery is intentional, however, is only evidence for imagery's being a form of thought if is also the case that sensations are not intentional, and Scruton nowhere argues for this further claim. He does say that the connection between imagery and thought in this respect "is brought out by the fact that one can only imagine what one can also think of'(p.100). It is not clear that this is enough, however; it could equally well be argued that one can only, in imagining undergoing sensations, imagine sensations, or collections of sensations, which one has previously experienced - in this sense, one can only imagine what one can also feel.

It is certainly possible to regard sensations as intentional; they represent the world as being some way. Unless it can be shown that this is not a plausible claim, then, as in the first two cases, the supposed feature which distinguishes imagery from sensation does not do so, but is fact consistent with imagery itself being sensational. However, if the intentionality of imagery can be spelled out in such a way as to make it a species of intentionality that cannot attach to sensations, then the objection can be met. If this is done then the fact that sensations are intentional will not entail that images are sensations. What is needed is a precise characterisation of the way in which images represent the world. This is of independent interest in any case; it is needed if a satisfactory understanding of experiential imagination is to be arrived at. The issue is in fact central to the whole project of understanding experiential imagination, and requires an extended treatment. A satisfactory account of the intentionality of mental imagery is needed to enable us to understand the sensory aspect of imagining something as being 
some way. The next section begins this by developing the distinction between what one's imagination-content is of, and what it is "as of". First, however, I summarise the conclusions of this section.

\section{Conclusion}

The common-sense view of imagination sees it as a blend of thought and experience. If this is to be defended then it must be done by working out the link between experiential imagination and intentionality. It is important to know what is meant by saying that experiential imagining has intentionality. I have argued that although Scruton's account is an attempt to defend the commonsense view it is not satisfactory as it stands. I have not denied that Scruton is correct to claim that thought components occur in experiential imagination. Also, he is clearly in a position to permit the occurrence within states of experiential imagination of non-intentional, non-thought components; (indeed, even if sensations are intentional, that does not in itself show that Scruton cannot still retain some non-intentional elements in his account). What is at issue is the precise nature of mental imagery as it features in experiential imagination and the reasons that one might have for holding it to be a form of thought. Scruton claims that images are of something and hence play a role in fixing the content of states of experiential imagination. However, Scruton's work provides insufficient grounds for concluding that imagery is a form of thought rather than purely sensational. I turn now to the "of"/"as of" distinction as a first step in trying to discover the link between intentionality and imagery. 


\section{THE "OF"/"AS OF" DISTINCTION}

In the story so far, experiential imagination has been presented as a particular way of representing the world; a way of thinking of things as being some way, (the way they actually are not necessarily excluded). A natural way of regarding these sorts of states sees them as blended out of imagery and thought. The previous section was sceptical about some reasons for believing in this blend, but endorsed some other ones with qualifications. As far as one putative mark of the thoughthood of imagery was concerned however, the discussion was inconclusive. That mark was intentionality, and I claimed that one can only point to the intentionality characteristic of states of experiential imagination as demonstrating their thoughthood if one can show that sensations are not themselves intentional. Whatever answer one comes up with to this question does not exhaust the interest of the intentionality of imagery, though. Given that the states at issue are intentional, the question naturally arises as to how the representing of the world characteristic of them comes about.

In this part of the thesis the representational capacity of the image is at issue; what is required is an answer to Wittgenstein's question, "What makes my image of him an image of him ?" (Philosophical Investigations, p.177) A good answer to this question should throw light on the elusive property or properties of experiential imaginative states in virtue of which they represent the world, and if one is clear on that point, a correct general analysis of these states should become easier to produce. Wittgenstein was unusually equivocal in ruling out one possible answer to the question of what it is about my image that represents him; "Not its looking like him" (ad loc.). But why not? A good place to begin this discussion is with the reasoning behind this answer - the reasons why my image's looking like him doesn't make it an image of him. 


\section{A Problem About Representation}

I will begin the argument with reminders of why one should believe that what one would think of as the same image can represent diverse singular contents. Here are two reminders, drawn more at less at random from a literature replete with them;

case 1; one imagines a suitcase, and then one imagines a suitcase behind which a sleeping cat is wholly obscured. (Taken from Peacocke, "Imagination \& Experience", p.19)

case 2; one imagines John with an obtrusive beer-belly. One then imagines John, pregnant. (Taken from Fodor, The Language of Thought, p.181)

In both cases, one imagines two different states of affairs, yet it seems clear that the same image will serve to fulfill both the miniature imaginative projects involved in each case. These are not the only projects which the two images could serve, either; the image employed across the two images in case 1 could equally well fulfill a project which imagined there to be a bomb hidden inside the suitcase, or a project in which one imagines one's suitcase as looking other than it actually looks, or a project revolving around the scintillating adventures of Suzy the sentient suitcase. And the image used throughout the second case befits an indefinite number of other singular contents too.

There is clearly a problem to be solved here, that of specifying the way in which an image can represent one thing rather than another. Wittgenstein's image of him, it seems, could just as well be an image of his twin-brother, or of some nefarious master of disguise impersonating his twin-brother. If an image can represent either one of a range of singular contents, the reason why it represents one rather than another needs to be established. One candidate, a causal relation, can be ruled out right away. Unlike memory images, there 
need be no causal link between what the image and some object previously experienced as looking that way. Nevertheless, we do imagine things specifically about an object, even in the absence of causal links with a previous (or current) experience of it. Similar considerations rule out testimony also. These remarks are intended to be neutral between externalism and internalism. If externalism is true then the content of my imaginative state must stand in some causal relation to the simple concepts which constitute that content. My point is rather the more straightforward one that one does not have to have experienced something as $\mathrm{Y}$ in order to imagine it as $\mathrm{Y}$; that sort of causal connection is unnecessary for succesful imagining. It is at the very least a racing certainty that no suitcase has ever been sentient, but the fact that experiences of sentient luggage are rarely met with is no impediment to the imagination. It is one thing to argue that imagination must be parasitic in some sense on perception, or other means of gaining information about the world. The claim being objected to here is the more implausible one that one must have experienced something as $\mathrm{Y}$ before one can imagine $\mathrm{X}$ as $\mathrm{Y}$.

So, a connection between a prior experience and an image is unnecesary for imagination. It is hence a bad candidate for explaining what fixes the content, and the image's looking like the imagined object does not alone guarantee that it is an image of that object. The situation is in fact more complicated than this, and the possibility of a certain sort of troublesome intended causal link with prior experience will later have to be faced. For the moment, the situation is thorny enough to be going on with. The point I take to have been proved is that the same image can be used in any number of distinct imaginative projects, and any given image is compatible with a range of ways in which the imagined object can be imagined as being, any of which can be imagined using the image.

\section{The Distinction Introduced}

There are two morals to draw at this point. The first is that images, in 
view of their startling versatility, are best thought of as type-images, which is what I shall take them to be hereafter. The second is that there is a distinction to be drawn between the object about which one is imagining something (what one's imagining is of), and the way that that object is imagined as being. In experiential imagination, the latter conjunct is as of the instantiation of sensory properties involved in an experience of the world as being a certain way. Hence, the "of/as of" distinction.

Now, the way in which the object is imagined as being is not simply constituted by an image. If it were, the elements of experiential imagining would be just the imagined object, and an image representing it as being one of an indefinite number of ways. This cannot be all there is to it, since the massive indeterminacy it introduces is not characteristic of experiential imagination. We know how we are imagining $X$ to be, buthon the basis of our knowledge that $X$ raher than $X^{\prime}$ or $W$, is what is being imagined. As well as the image, then, we need to think of the "as of" as including the descriptive label; this label will advert to the imagined object, and say how that object is imagined as being, this being effected by the image.

The distinction, then, amounts to a difference in the elements of experiential imagining. However, it is the latter, the "as of" part, which is distinctive of experiential imagining - an imaginative project may be about the Guinness Brewery without employing images and their accompanying labels. In such a case the image is absent, and so the propositional contents of the experience specify what is being thought about the object in a different way. They are employed to do their work of saying what is being imagined about the Guinness Brewery, but because no images are present in the episode, they do not act as labels. Such non-labeling non-sensory contents may also occur in projects employing imagery. For instance, one may imagine the Guinness Brewery as looking like the Beaubourg, and (a)entertain the relevant image. As part of the same project one may also (b)imagine that tourists would then go to that part of Dublin for architectural as well as bibulous reasons. In this case, 
the label need say no more than that the image in (a) is the Guinness Brewery imagined as being a certain way ("say" should not be taken to imply that the label must be a proposition explicitly entertained at the same time as the image is enjoyed). However, since (b) can be imagined without images being employed, the relevant propositions which are entertained are not in this case labels. If images were employed, however, perhaps of coach parties assembling outside the Brewery, then of course further labels would be part of the project. It is wrong, though, to think that any one project must consist of all and only episodes which are experiential or non-experiential. Projects can be mixed.

There are thus a good deal of further distinctions which could be drawn as the relation between imagining and experiential imagining is refined. Such distinctions are orthogonal to the main one which is being considered here; the "of/as of" distinction. The present point is only that the image and accompanying label lie on the "as of" side of the basic distinction within experiential imagining which I have drawn. (The label, though, mentions the object which the imaginative project is of).

The "of/as of" distinction captures a difference in the elements of sensory imagining. The "as of" part is the more important; it represents what is distinctive about experiential imagining considered as a type of mental operation. To get clear about it it is necessary to work out the details of two relationships. The first is that between the label and what might be called the "sensory core" which the label describes. The second relation which must be clarified in order to understand experiential imagination is the one which obtains between the sensory core and perceptual experience.

Before turning to these two tasks, I want to introduce the complication which I mentioned earlier. It seems possible to imagine something about, e.g. King's College, whilst entertaining an image as of a wholly different experience, ie. an experience of another particular. Now this can obviously be done with intent, as an episode in the imaginative project; so one might 
imagine King's College as looking like the Guinness Brewery. The troublesome case however, comes not when one is imagining the object as looking other than it actually does, but when one has a false belief about how it looks. Corresponding to this false belief is a false belief about the sensory experience which is enjoyed by a perceiver of the imagined object, and a consequent image that is sensitive to the false belief rather than the imaginative project. Although one takes oneself to be imagining the object as it actually looks in these cases, one is unwittingly failing to do so. So, if the imaginer has been in perceptual contact with Somerset House, but mistakenly supposes it to be King's College, she can subsequently imagine things about King's College, whilst at the same time enjoying an image of Somerset House. I shall go into this in greater detail later on, suggesting that there is sufficient uniformity in the way this problem is treated to permit talk of there being a standard account. This standard treatment of these cases need not be completely accepted. However, much of the standard account seems to be correct. I shall set the standard account out, and then indicate where one may presume to part company with it over this issue.

\section{The Relation Between Image and Label}

In addressing the first question, that of the relation between image and label, it is as well to remember the function that labels serve. I will go over more fully some ground already dealt with, showing first the necessity of an appeal to labels, and then investigating the form of the standard account of the relation.

The argument so far has depended on the claim that labels are required in order that the image may represent a singular content. There could be some resistance to this as a general account however, if an objector thought that in at least some cases the relation between sensory core and object of imagination required no label to fix it. The suspicion might be that in some cases the 
resemblance between image and object might be sufficient on its own. This might be dependent on a belief that depiction generally could be supported by resemblance. Rather than a solution from depiction assisting in the case of imagination, however, the converse is the case; the same difficulties which Witgenstein and later philosophers have fastened onto in the case of mental images cause trouble in the case of depiction generally. There is not simply a problem about mental imagery, but a more general one about depiction. Thus when Pitcher asks "why can't a mental image of a piano, say, be like - i.e. resemble - a piano, in the perfectly straightforward way in which a painted picture of a piano is like a piano ?" (G. Pitcher, Berkeley, p.116), his question is informed by the false supposition that there is some simple relation of resemblance which obtains between pictures and their depicta. If there is such a straightforward depictive relation of resemblance, then it might seem that labels are unnecessary; an image, like a picture, will represent its object in virtue of resembling it.

Strictly speaking, Pitcher's suggestion, even if successful, would do no more than show that labels are not a necessary condition for imaginative representation. There will still be cases in imagination of images representing objects which they do not in any sense resemble. It might then seem that labels are required in order to explain these latter cases, but that the other types of case, in which a mental image of $\mathrm{X}$ as it actually looks accompanies one's imagining $X$ as $Y$, is explicable in terms of resemblance.

There are well-known problems standing in the way of any explanation of depiction in terms of resemblance, however. Goodman pointed out (Languages of Art, ch. 1) that a picture always looks more like another picture than it looks like any non-picture. The relevant properties are not just the ones which Pitcher regards as making the claim that a picture resembles another picture (or an image another image) trivially true (Pitcher, loc. cit). Pitcher calls these essential properties, and presumably has in mind non-visual properties, such as, perhaps, ones pertaining to physical constitution or dimensions. 
Goodman's point is wider; even those visual properties had by the image or picture, such as the arrangement of colours, will make the icon more like another icon than like any depictum. Even philosophers who appeal to resemblance do not regard it as sufficient for depiction. (cf M. Budd, "How Pictures Look"; Budd holds that if A depicts B, the visual field caused by an inspection of $B$ is isomorphic to that caused by an inspection of $A$. This on its own does not suffice for resemblance, and anyway hardly seems to be the straightforward sort of relation Pitcher appealed to. A similar treatment to Budd's, but without the commitment to "looking like" can be found in Peacocke, "Depiction", Philosophical Review, 1987, pp.383-410))

So, a picture of a bear will resemble another bear-picture just as much reseurbes as it represents a bear. It will also depict a man in a bear suit, or an alien from a planet where all the inhabitants look like bears, or a member of any generally bearlike species. What these will all have in common is that they look like each other. The same applies, mutatis mutandis, to images comprising the sensory core of the "as of" components of experiential imaginative states. A sceptic about labels might nonetheless still want to deny that labels are always required. Such a sceptic might argue that we can only make sense of labels occurring in some areas if there are areas in which they do not occur. It might be felt that labelling cannot explain the relation between image and object, but only specify certain non-standard cases of it, on the assumption that the standard cases can be understood without introducing the notion of labels at all. It is of course consistent with such a view that what it thinks of as the standard cases might be comparatively uncommon compared to non-standard cases. The view would simply mark off a class of cases as standard and regard labels as doing the job of specifying how the standard relation is altered in a particular case.

The great difficulty in this is finding a standard class; indeed, I fail to see how it could be done. Take the earlier case (2), (p.36) which made use of a image of John with a bulging stomach to represent John as fat and also John 
as being pregnant. Certainly the former is most often met with in the world, but this scarcely seems enough to warant regarding it as a standard piece of imagining. For a start, there seems little reason to believe that a standard case of imagining need be about a commonplace, rather than an unusual, situation. Furthermore, there will be many cases in which the same type-image can be used to represent two commonplace situations, such as Mary asleep or Mary dead. Indeed, even imagining John as fat might be too coarse-grained to capture the content of some imaginative episodes; one might wish, in imagination, to distinguish between John who got fat through overeating, and John who got fat because of a glandular disorder.

Some properties, such as being pregnant, might be thought of as not purely perceptual properties, but one which is inferred on the basis of the purely perceptual property of being a certain shape. One might think that further information is required, beyond a mere specification of how a person's fleshy contours look. Perhaps this distinction could be employed to fix the standard cases; the thought would be that the standard cases are those in which the purely perceptual properties of the image match those of the object. This would restrict the standard cases very severely, to those in which the way something is thought of as being are given in imagination purely perceptually; as being shaped or coloured a certain way. Despite this tight restriction, however, it would clearly remain possible for there to be any number of objects having the same purely perceptible properties of the image. Now, since the only properties allowed to be specified in the elucidation of a standard case are purely perceptual, there will be no way of knowing which object is represented. Being an object of a certain type, let alone a token of that type, is not a purely perceptual property, so using such properties gives no clue to the object being thought about. If a device were rigged up which could scan my brain and project my mental images onto a screen, observers would be aware of the purely perceptual properties of the images they were confronted with, but not the objects which those images represented. Inspecting such projected images would be like being in an art gallery in which there are no titles, nor 
any other means, to tell the viewer what the pictures depict. There is no substitute for labelling.

\section{The Provenance of Labels}

Standard accounts look upon the image as labelled according to the project in which it features. I have already touched upon the ways in which different philosophers treat of these projects. The standard idea regards the intentions of the imaginer as supplying the label. Relative to the project, the label says which object is being imagined, and specifies the way in which it is imagined. The ways in which the label is thought of vary from philosopher to philosopher; closest to my formulation is probably Walton's idea, which sees the label as deriving its character from the rules governing the imaginings which the subject is embarked on at the time (see chapter p.17).

The label must satisfy the requirements of mentioning the singular content and specifying how the image is to be interpreted as about that content (what Fodor calls taking the image "under a description", op. cit. p.190). Beyond this, it is probably folly to try to seek further necessary and sufficient conditions for the label; certainly, being explicitly entertained by the imaginer concurrently with the image seems unnecessary, and perhaps also insufficient. The label gives us knowledge of the content of the episode, but, as Wittgenstein noted, the connection between label and image might be established not at the precise moment the image is entertained, but at some other time (Blue and Brown Books, p.39)

Since the label mentions the object imagined, and ties down the type-image to that object, it is natural to assume that the label is intimately connected with the imaginative project in which the episode employing the image crops up. It also seems natural to assume that the label always establishes a relation between image and object; this assumption follows from the image's being apt to represent any number of different objects. It might seem that however seemingly unlike the imagined object the image is, the label 
will always do the job of specifying, of that image, that it is of the imagined object. Not only that, but the label is put in place courtesy of the imaginer. Hence, it seems, the imaginer can never be wrong. The label is always able to reconcile any sensory core with any object if it specifies that the object is being imagined in this way, and the imaginer's intentions fix the label. Therefore. the imaginer's intentions always make it the case that the object of the imagining is being imaged, no matter how different the veridical experience of the object is from the instantiation of the properties of the sensory core in veridical perception.

This conclusion might seem necessary if one is to reconcile two facts. The first is that we know what we're imagining; as Wittgenstein noted, there seems no doubt but that even though one's image could fit many objects equally well, one does know what one's imaginative episode is of. Even though my image of King's College on fire could fit many other blazing objects, still one unhesitatingly refuses to doubt that one is imagining King's College, and not one of those other objects. (Wittgenstein, ibid, p.39) The second fact is the evident possibility that one may set out to imagine something and seemingly get it wrong. Consider the sort of case covered by the deviant causal link mentioned earlier; a tourist might mistake Somerset House for King's College (London, of course, rather than Wittgenstein's Cambridge, to keep the story simple). Suppose that ever after this misinformed traveller, imagining King's College, conjures up mental images of Somerset House instead. One might want to say that in this case our heroine intends to imagine $\mathrm{KCL}$, but fails in that intention and unwittingly summons an image of Somerset House. The worry is that failure of image amounts to failure to imagine KCL at all. The argument outlined in the previous paragraph is supposed to deflect this by showing that the label, stemming as it does from the imaginative project, acts as a kind of insurance against such error. The presumption is that the imaginer's label is provided by what she is thinking, knowledge of which is indubitable, and so the label ties the errant image to the object. In various different guises, it is is the standard answer to the worry 
dramatised by the case of the mistaken tourist.

No account of the relation between image and label will be persuasive until it soothes the worries this case provokes. It is necessary then to see if the standard account is soothing or not before opting for it as the correct general account of the relation between image and label.

That the standard answer is indeed standard can be seen by looking at the literature. James argued over a century ago that the subjective difference between perception and imagination was less than that commonly supposed to hold, and that the same sensation of vision could be of different objects according to the "interpretation of the mind" (The Principles of Psychology, p.718) The recent discussion of labels has often started from Wittgenstein, whose discussions on this topic I mentioned above. Fodor and Peacocke, for instance, both explicitly acknowledge a debt to Wittgenstein.

Worried by the question of whether the image and the imagined object can come apart, philosophers have sought to rescue for the imaginer the fruits of her mental activity by setting up an account of the imagination in which the subject drives the labelling, which can make any image, no matter how far in conflict it is with the imaginer's beliefs, represent any object. Two things are rescued by the standard account, in fact; the imaginer's knowledge of the imaginative project, and the general truth that an image can represent any singular content. But this double rescue is effected at the cost of abandoning the link with belief. Our misguided tourist genuinely seeks to image Somerset House, because in doing so she believes herself to be contributing to her imaginative project of imagining things about King's College, but she takes herself to be imagining King's College as it really is. If the label must show how $X$ is imagined as being $Y$, then in this case, in order to preserve the sort of infallibility with respect to imagination which the account wants to preserve for the imaginer, the label must contradict the project; the label says that King's College is imagined as looking like Somerset House as part of the 
project, but any intentions about the project which the imaginer has will not include the intention to imagine King's College as looking like Somerset House. In fact, the imaginer's intentions might include the entirely contradictory intention to imagine King's College as looking like itself. Because the standard account of these matters holds the label to be sensitive to the project, and holds too that the label is always capable of reconciling any image with any singular content, it renders problematic the question of whether, and how far, the imaginer's beliefs and intentions count

There is a clear sense in which one is not mistaken about what one is imagining. There is, as Peacocke says, an absurdity inherent in even asking somebody whether she really is imagining the object she takes herself to be imagining. ("Imagination, Experience and Posibility", p.26-7). Peacocke also points out that the intended object need not stand in any causal relation to the image. Therefore, imaginers might be mistaken about the object their image is causally of. But, since this sort of error can occur, the way is still open to impute infallibility to the imaginer by pointing out that the label can reconcile the image with the imagined object; since no causal relation need be relevant, no causal relation need be taken into account into specifing what the experiential episode imagines to be the case. This, I argued above, makes the imaginer's beliefs irrelevant, as well as the actual causal link obtaining in the world.

A different treatment, amending the standard account slightly, would need to make room for the absurdity of ascribing error to the imaginer with regard to the object imagined, but make room for the imaginer's beliefs to infect the sensory core. Such an account would say that the episode is still an imaginative episode about a certain object, even though the image is not of that object in the way required by the project, and is therefore, in a sense, mislabelled. Such an account leaves the imaginer as the final court of appeal with respect to her own project, but allows a certain degree of error, consonant with her mistaken beliefs, about the way the image fulfills that project. To 
indicate what such an account could be like, one might reflect on a case of veridical perception in which the same elements are in play.

In such a case, a subject may stand in front of Somerset House, wrongly believing it to be King's College. Suppose that our heroine has all sorts of true beliefs about King's College, and that some of these beliefs are actually entertained by her, in the course of a long mental disquisition on King's College, while she observes Somerset House in the mistaken belief that it is King's College. It is not necessary that she actively entertain the sentence "this building before me is King's College" at any time during this passage of mental activity. That belief is simply something lying behind the whole episode; it is in fact the mistaken belief that is responsible for her positioning herself at that particular point in space, one from which Somerset House is clearly perceivable.

What ought we to say about such a case ? It seems quixotic in the extreme to deny that our subject is thinking about KCL simply because a false belief about its appearance has caused to stand in the wrong place. If it were not for the fact that Somerset House is salient the question of her not thinking of KCL would not arise - if she uttered her thoughts she would naturally be interpreted as talking about KCL. She could be in exactly that same spot, perhaps in a heavy fog which obscured the surroundings, and no question of her being in error would arise. And someone who corrected her would be likely to point out that she was looking not at KCL but at Somerset House. To do this it would be necessary to interpret her thoughts as about KCL. If, on the basis of her looking at Somerset House, one took her to be thinking about it, the correction would take the form of telling her that she had all sorts of strange beliefs about Somerset House. From the point of view of interpretation, it is clear that her talk of KCL is a better guide to her thoughts than her staring at Somerset House.

Here we have a case in which someone's experience and thoughts are 
at loggerheads, but it is clearly the latter which are the maypole around which interpretation revolves. The same approach ought to be used in the case of an individual who images $Z$ whilst her project leads her to think of $X$ as $Y$. It is entirely legitimate, indeed it is much the most sensible option, to treat the imaginer's project as specifying the object of the imaginative episode, whilst at the same time conceding that her false beliefs about that object's appearance have led her to conjure up an image of a different object, to wit, the object which stands in a causal relation to the image, mediated by her beliefs.

Such a treatment secures what the standard treatment sets out to secure; it ensures that there is an absurdity involved in questioning an imaginer's knowledge of what her imagining is about. This is because the imaginer lays down the project, and therefore knows what it is and what it entails (this is consistent with the project evolving as time passes and the imaginings continue). On the other hand, it puts the imaginer's beliefs back into the picture. An appeal to one's knowledge of what one is thinking about (i.e. one's current imaginative project) does not show that one's image is of what one takes it to be, any more than an appeal to one's knowledge of what one is thinking about (i.e one's occurrent beliefs) shows that one is seeing what one thinks one is seeing.

There seems to be a case for using this treatment rather than the standard treatment to explain such a case. However, we should not expect every case to be amenable to the same procedure. The treatment I have proposed will do for certain cases in which one misidentifies what one is imagining which the standard treatment deals with poorly. There will be further cases, however. We ought not to rule out cases in which it will just be indeterminate what the subject is thinking of; this might come about because of both the intended and the actual object playing a role, for instance. There might well also be cases in which the tourist intends to imagine what is salient ("what if this looked like the Beaubourg ?"), and to do it by recollection, but despite possessing the appropriate knowledge, the object is misidentified and 
hence misdescribed. The moral is that the standard treatment fails to respect the variety of possible cases. In one case, I have suggested, it can be amended to save what is wanted without misrepresenting a possible experience. Things will not always be so clear cut.

\section{Conclusions}

For any particular-directed content of experiential imagining, the sensory aspects alone do not contain who or whatever it is that one is thinking of. The phenomenological sameness which can obtain across some experiences is a reminder of this. The fixation of content requires the application of a label.

It is now time to wonder about the consequences of accepting the image \& label picture of imagining "as of" which I have outlined. An understanding of how the singular content gets into the episode is in place; it is done through the label's mentioning of the object of imagining. There is still no account of the relation between image and perceptual experience. It is to this question which I now turn. 


\section{PEACOCKE ON "AS OF"}

Early on in the preceding section two questions about imagination "as of" were distinguished. The first of these was the question of the relation of the sensory core to the descriptive label, they being the two elements which comprise imagination "as of". The second question had to do with the relation between the sensory core and perceptual experience. An account of the way in which a specific singular content gets into the imagining emerged as an answer was sought to the first question, that answer seeing the label as mentioning the imagined object, and specifying the way in which the object was imagined as being. That specification, it was argued, is dependent on the constraints governing the imaginative project within which the imaginative episode occurs.

An answer to the second question was postponed. It is this question with which the remainder of the thesis will be centrally concerned. There is a clear, intuitive, sense in which experientially imagining something is subjectively like seeing it, and the same is true of imaginative states which are related to the other senses. The question is how the apparent subjective similarity between perceptual states and imaginative states is to be explicated; what is the relation between image and veridical experience ? There are, in an admittedly rather scanty literature, two main approaches to this problem. One, which I shall come to in the next section, where it is personified by Hugh Mellor, is in accord with the picture of imagination as a means of representing the world which I have assumed to be the commonsense understanding. Before attending to that approach, however, I want to consider a rival one, stemming from Peacocke's work. Peacocke brings out the connection between perception and experiential imagination by viewing the latter not as representing the world but as evoking, in a manner I shall make clearer later on, a perceptual state. On this view, to be in a state of experiential imagination 
is to imagine an experience, i.e to imagine oneself, rather than the world, as being some way.

If Peacocke's view is correct, then, it provides a good reason for supposing that the commonsense conception of experiential imagination, as I have presented and developed it, is either in error or not in fact the commonsense conception at all. The latter is Peacocke's view; he presents his account as less a theory of the sensory aspects of imagination than the drawing out of certain consequences of our concept of these states. The first reason for placing Peacocke at centre-stage during this part of the action is thus that he presents a challenge to the understanding of experiential imagination which I have claimed to find in our concept of it.

The second reason I have for looking at Peacocke's work on this topic here is that he accepts a picture of the way in which the singular content of a state of experiential imagination is fixed which is very similar to the one I have outlined as the standard position on this topic, and made use of myself; certainly, the same elements are in play. Peacocke thus answers the first of the two questions stated above roughly as I have; it will be necessary, therefore, to see if his answer to the second question is independent of the answer given to the first. If it is not then the appeal of that answer will be a good reason for accepting Peacocke's view; if it is independent, then we can rest content with the answer to the first question, and consider Peacocke's as a putative response to the second.

\section{The Elements Of Peacocke's View}

I shall begin by giving the main points of Peacocke's paper, before going on to develop a positive account out of it, which will then be criticised. Peacocke seeks (in "Imagination, Experience and Possibility") to elucidate the connections between imagination, experience, and possiblity. After remarking that he is concerned not with the term "imagination" in all its various uses, but 
solely with a phenomenologically distinctive state (corresponding to my "experiential imagination") Peacocke states his General Hypothesis;

to imagine something is always at least to imagine, from the inside, being in some conscious state. (op. cit. p.21)

Straightaway, then, Peacocke links imagining $x$ to imagining a state of mind of some subject, since conscious states do not exist unattached to a bearer (or even if they do, the ones we can imagine don't) This, he claims, is a "conceptual truth" (p.21).

The General Hypothesis does not itself explain, thinks Peacocke, the relation between perception and the sensory core of experiential imagination. What it does do is link such states with what he calls "the first-person way of thinking of oneself" (p.21). That is, imagining something in this way involves imagining something about oneself. That does not mean that it be laid down by the label that the subject, him- or herself, is always the individual whose experience is imagined; that would be very difficult to defend convincingly, since it is obviously possible to imagine seeing oneself featuring in a scene of which one is a spectator. What the General Hypothesis requires is that the imagined scene is always imagined as from a point of view, such that someone occupying that point of view would be able knowledgeably to judge "I'm thus and so", where the "thus and so" gives details of how things are at the viewpoint, and the "I" which judges refers to the occupier of the viewpoint. This requirement is met by supplementing the General Hypothesis with the further conceptual truth that it is epistemically impossible for any thinker to entertain the content "I am not the person with these conscious states", where the conscious states referred to are made available to the thinker in virtue of his actually being in them. The conscious state which the General Hypothesis stipulates an imaginer to imagine herself in is presumably such a state, as well as the state of imagining, which will of necessity always be a state of the person in the real, rather than the imagined, world. The former, which gives 
the content of the imagining, is what is directly at issue; that is the state whose first-person character is being elucidated.

Having described what he takes to be the connection between the sensory aspects of imagination and the first-person way of thinking, Peacocke goes on to advance a constitutive hypothesis, which he regards as uncontroversial, about the conceptual connection borne to experience by such imaginings as "visualizations, hearings in one's head, or their analogues in other modalities." (p.22). While the General Hypothesis tells us that "imagining is always imagining from the inside being in some conscious state $(\phi$, say)", the Experiential Hypothesis covers the more specific states; visualizations and the other sensory imaginative states. It runs as follows;

to imagine being $\phi$ in these cases is always at least to imagine from the inside an experience as of being $\phi$

Some conscious states falling within the ambit of the General Hypothesis are not covered by the second hypothesis. Peacocke instances the difference between imagining playing the Waldstein sonata, which is the sort of state covered by the Experiential Hypothesis, and imagining one's hands hitting the keys as the notes sound. The conscious, subjective components of intentional action which occur in the first case are not covered by the Experiential Hypothesis.

Having produced his two hypotheses, Peacocke uses them to answer three questions which he has posed previously. The first question is what he calls the question of the "image/imagination distinction". An example which introduces this question is the one I mentioned earlier - the same conscious, subjective image can be employed either to imagine a suitcase, or to imagine a suitcase obscuring a cat. The second question Peacocke is concerned with is that of fixing singular content; imagining King's College rather than its exact 
replica. Thirdly, Peacocke is exercised by Bishop Berkeley's notorious assertion that it is not possible to imagine an unperceived tree.

The answers which Peacocke gives to the first two questions are roughly the same as the answers which have emerged earlier in the thesis, answers which resonate with the proposals offered in the wider literature. The first two questions are answered by an appeal to what Peacocke calls S-imagining. (' $\mathrm{S}$ ' for "suppose"). The same image can be employed in the following three cases; imagining being at the helm of a yacht: imagining from the inside an experience as of being at the helm of a yacht: imagining from the inside what it would be like if a brain surgeon caused one to have an experience as of being at the helm of a yacht. In all three cases the image and the other sensory aspects can be invariant (one need not imagine anything phenomologically different in any of the three cases). The differences in the three cases are secured by the conditions that are S-imagined to hold in the imagined world; in the first case "it is imagined that the experience is perceptual; in the second it is left open; in the third, it is imagined that it is produced by an intervening brain surgeon". (p.25) What is S-imagined, like what is supposed, is not determined by the subject's imagined experiences.

S-imagining plays the role in Peacocke's picture which the rules laid down for the imaginative project play in Walton's (see my earlier discussion of the latter's Mimesis As Make-Believe, at p.17). Just as it is probably simplest to see what is S-imagined with respect to a given image as the image's label, what is S-imagined about the role played by the image in an imaginative project can be seen as an extension to a particular imaginative episode of the rules put in place by the imaginer to govern an imaginative project. The experience is imagined in order to fulfil conditions which the imaginer wishes to see fulfilled in order to further the project.

S-imagining also helps Peacocke to answer his second question, that of the content. Because a subject knows what object she is S-imagining to produce 
her image, there can be no question of her imagining that she is seeing a replica of King's College, rather than King's College itself - the knowledge of what is S-imagined to hold is secure because it is simply a case of our general knowledge of what we are thinking. Here again, S-imagining can be assimilated to the account given earlier of the way in which the label fixes the content of what is imagined. This is as it should be, since the proposals put forward earlier (allowing for slight quarrels over the extent to which image and label can come apart) was supposed to harmonise with the general approach taken to these questions, and Peacocke's is a specimen of this more general approach.

So far, Peacocke's account of S-imagining is in accord with the picture suggested by the understanding of imagination I have claimed to derive from comon-sense. It is when one puts S-imagining together with the hypotheses Peacocke has advanced that it starts to become detached from that picture, under the influence of the hypotheses, which are themselves contrary to the spirit of what I have been arguing for. The results can be seen by reflecting on the answer Peacocke gives to the third question; Berkeley's. Given the requirements of the Experiential Hypothesis, Peacocke has no choice but to endorse Berkeley's contention that one cannot conceive of an unperceived tree, at least if conceive is read (as Berkeley meant it to be), as "experientially imagine". (When Hylas concedes that he cannot conceive of an unperceived tree, he admits that it is because there can be no more to conceiving than entertaining images; "all I can do is to frame ideas in my own mind" (Berkeley, "Three Dialogues Between Hylas and Philonous", First Dialogue, p.200, in G. Berkeley, Philosophical Works, ed. M.Ayers. A.D. Smith has argued that all thought, for Berkeley, is iconic; see his "Berkeley's Central Argument" in Foster \& Robinson (eds) Essays On Berkeley, pp.37-57) It seems to me that the counter-intuitive consequences of what Peacocke takes to be his uncontroversial understanding of our concept of experiential imagination can be brought out in the first case by focussing on this question. 


\section{Berkeley's Question}

Because it is in the nature of experiential imagination that imagining is, in part, to imagine an experience from the inside, the sensory core of any episode of experiential imagining, must, on Peacocke's view, represent such an experience. This can be seen by considering the examples given above of helmsman-like experiences; in all three cases, what Peacocke takes the type-image to represent is one of a range of possible experiences, put to different uses according to the subject's project. In no case, on Peacocke's understanding, can the type image merely represent the world as it would be experienced from the helm of the yacht; it rather represents an experience, and that experience may be of the world as seen from that point of view. It may equally well merely be as of the world seen from that point of view, as in the case of one's imagining an experience as of being at the helm of a yacht produced by an accomplished neurosurgeon.

The sensory core is always connected to a state of mind. This state of mind could obtain independently of whether or not the world actually is as that experience represents it as being. The question of the way the world is is a further issue, not given by the image but settled by the S-imagined constraints. Now, when Berkeley asks us to imagine an unperceived tree, says Peacocke, he requires us to specify, as part of the project, that there is a real tree in the imagined world. Therefore, if Peacocke is correct, when one tries to meet Berkeley's request one imagines an experience as of seeing a tree, and specifies that there is a real tree in the imagined world. To combine these two conditions with the further condition "that in that imagined world no tree is perceived is to place inconsistent conditions on the imagined world; and that was precisely Berkeley's conclusion" (p.28).

The upshot is then that to imagine a tree one's image must represent the tree, and this must be the singular content laid down by the label. However, the sensory core represents not the world directly, but an experience as of the world's being a certain way. The content of that experience is laid down by 
the label. In this case the label lays it down that the experience is of the tree; hence it must be an experience which represents an actual contemporary state of affairs, in other words, a veridical perceptual experience.

If Peacocke's general understanding of experiential imagination is the correct one, therefore, it supports Berkeley's conclusion. This is only one of a number of consequences of this particular understanding of imagination which seem to me to be in no way plausible. These counter-intuitive consequences do not stem from regarding images as types requiring a labelling according to the constraints imposed by an imaginative project. That understanding of the relationship between image and project would be true even if images represented the world as being some way; in other words, that picture is unaffected if experiential imagining does not, as Peacocke suggests, involve imagining a state of mind. The truth or falsehood of the General and Experiential Hypotheses are thus the key to resolving this dispute. If they are true, then the correct answer to the question of the connection between sensory core and perceptual experience is to be found in them. The answer to the the question of the relationship between experiential imagination and perceptual experience is thus independent of the image/label relation, and also less pressing, since it can accommodate either the commonsense view or Peacocke's view. Accordingly, I turn now to a more detailed investigation of Peacocke's paper, to see whether what I have called the commonsense view of imagination as a representative state needs to be replaced by Peacocke's view.

\section{The Peacockian Theory}

Examining Peacocke's view is not entirely straightforward; he does not put his proposals forward as a theory. Rather, he regards his two hypotheses as conceptual truths, and sees himself as bringing out certain consequences of the concept they are true of. Far from being conceptual truths, Peacocke's hypotheses seem to me to be at least contestable, and in fact almost certainly false. To see why, though, it is necessary to reconstruct his remarks into a theory, which I can call the Peacockian theory, of the connection between 
states of experiential imagination and perceptual experiences. (Peacocke himself acknowledges that his remarks form the outline of a general account (p.19). It is possible to attempt such a reconstruction on the basis of the examples I have given so far.

The Peacockian theory can be summed up as follows. When one imagines $\mathrm{X}$ as $\mathrm{Y}$, what one is imagining is the experience. The experience is an experience as of $Y$. In those cases in which the constraints governing one's imaginative project lay down that what one is imagining is the world's being some way, rather than oneself undergoing an experience which could be entertained regardless of how the world is (such as imagining a hallucination), then what one imagines is a perceptual experience; one imagines being a perceiver of the imagined state of affairs, from some point of view relative to it, since perceptual experience is always from a point of view. This contests what I have been assuming, on the basis of commonsense, needs to be explained. It denies that imagination represents the external world as being some way, and argues that our conception of experiential imagination sees it as a state in which one imagines an experiencer, within the imagined world, as undergoing an experience of a certain type.

I turn now to criticising specific features of the Peacockian theory, starting with the General Hypothesis. Firstly, there seems to be some reluctance on Peacocke's part to spell out exactly what "imagining from the inside" amounts to. It is clearly not a requirement that the experience which is imagined be one which involves all that normally goes on in perception. As well as the object of one's perceivings one is normally aware, example, of the position of one's own limbs and sundry other bodily parts. It would be very implausible to maintain that experiential imagination requires these kinaesthetic experiences, and of course Peacocke is not in the business of asserting that they are required. Nor does it seem to be part of what Peacocke means by imagining from the inside that the experience has to be somebody's experience; it is the S-imagined constraints, it appears, that specify that, for 
example, there must be a perceiver, if there is to be a real tree which is imagined.

What, then, is Peacocke saying about imagining from the inside? The simplest way to understand it is as designed to rule out a certain type of case. The type of case I have in mind is one such as this; I imagine myself as being in pain by imagining that I am someone else looking at myself screaming and writhing on the ground. Cases like that are ruled out by the requirement that imagining be from the inside. It seems to me, though, that there may be a further aspect to imagining from the inside which is at least suggested by Peacocke's remarks. What it comes to has been touched upon already. Peacocke uses "from the inside" to indicate the connection he detects between imagining and the first-person way of thinking of oneself; "imagining always involves imagining from the inside a certain (type of) viewpoint, and someone with that viewpoint could, in the imagined world, knowledgeably judge I'm thus-and-so, where the thus-and-so gives details of the viewpoint." (p.21) Clearly one can give details of a viewpoint without occupying it onself; I can say what it is like to gaze down over London from Parliament Hill without currently being there myself. But in doing this I'm not saying "I'm thus-and-so", but "I might be, or have been, or one could be, thus-and-so". It is the combination of first-person pronoun and present tense which secures the first-person element in experiential imagination for Peacocke. However, Peacocke also uses the locution "imaginings always involve yourself". I do not think it is clear whether the quotation I gave above explains this or the concept of imagining from the inside, or both. It seems easy to understand how, given the first-person judgement Peacocke adduces, one might understand imagining as being about oneself. It is perhaps less clear why this should be thought of as imagining from the inside.

"Inside" seems easier to grasp intuitively than to spell out in detail. The intuitive way of grasping it appears to me to be to think of it as trying to convey that the sensory aspect of experiential imagination has a certain sort 
of "feel" to it, similar to that which a non-imaginative experience has; perhaps support for this interpretation comes from the alliance Peacocke forges between the General Hypothesis and the fact that no thinker can doubt the truth of "I am the person with these conscious states." The reason why this content is rationally indubitable is that the conscious states it speaks of are made available to the thinker in virtue of his actually being in those states. Now, it seems that when one is in a certain state one is not only enabled to make judgements about it. It seems that there is also something which it is like to be in a given state. There is a difference in what it is like to be in a darkened room, for instance, rather than in a room which is fully illuminated. However, no assertion which the person who is enjoying the experience can make seems able to convey to someone who has never enjoyed it what that experience is like. Perhaps the best way to think of imagination from the inside is to see it as evoking this aspect of experience. Just as someone who has never had an experience of a certain sort, such as being at the helm of a yacht, say, is unable to fully appreciate what it is like, so we might suppose that if you have never crewed a yacht, you will not know what crewing a yacht is like, and thus not be able to imagine crewing a yacht.

\section{The General Hypothesis $\mathcal{E}$ the Experiential Hypothesis}

The trouble with this interpretation is that it might seem to cover the Experiential Hypothesis much more convincingly than the wider General Hypothesis. Peacocke admits that there is a sense in which if one has never played the Waldstein Sonata, and hence has no idea how to play it, one cannot imagine really playing it, rather than, for instance, simply imagining hitting the keys and hearing the appropriate tuneful sounds mysteriously issue forth. There is a clear difference in what it like between these two experiences, so one might think that as the actual playing of the Waldstein is covered by the Experiential Hypothesis, my interpretation of imagining from the inside ought more properly to be reserved for the unpacking of the Experiential Hypothesis. 
One can see why the putative objection in the preceding paragraph flounders however, if one reflects on sitting at a piano, banging away more or less at random on the keys in the manner of the late lamented Les Dawson, and hearing the sounds of the Waldstein Sonata enchanting one's ears as a result. This is no doubt rather far-fetched, but it could be a possible experience; it certainly seems that one can imagine it happening. Now, if it were to happen, then there would be something that it would be like to have that experience. Since there would be something that it would be like, this sort of case is no bar to interpreting "imagining from the inside" as denoting imagining which involves a certain phenomenal feel. The reason for this is that one is imagining an experience such that if one were to have that experience, one would thereby enjoy that phenomenal feel. Just as in the case of imagining playing the Waldstein, it would make sense to talk in the key-banging case of the visualisations and auditory imaginings appropriate to the experience. These would be covered by the Experiential Hypothesis. The feeling of agency would differ in the two cases, but this is not a visualisation or an analogue of one, and hence would not be covered by the Experiential Hypothesis. An interpretation of "from the inside" in terms of what it would be like is thus not restricted to the Experiential Hypothesis.

Note that in saying this I am not claiming that Peacocke thinks that when one imagines an experience, one is in a state which shares any qualitative or representational properties with an actual experience. The position is that in experiential imagining one imagines an experience, and that experience has certain representational properties (and, thinks Peacocke, sensational properties also (see his Sense and Content, ch.1)). If the viewpoint is simply a position relative to the object of the imagined experience, it seems that the same viewpoint could be occupied by an individual undergoing any one of a number of different type-experiences. Imagine looking at King's College under normal conditions; now imagine occupying the same viewpoint, but looking at King's College through rose coloured spectacles, or when it is enshrouded in mist. 
It is not shared properties of an exercise of the imagination and an exercise of the senses which are doing the work of making the sensory aspect of experiential imagination like experience, according to the Peacockian theory. The work is being done by the fact that in imagining one imagines an experience; it is an appeal to this wider, previously understood notion of imagination that is doing the work. One is not imagining the world as being some way; what is being represented is, if anything, a state of the subject, which, when actually realised, represents the world as being some way. This is what is meant by the Experiential Hypothesis when it decrees that to imagine being $\phi$ is to imagine an experience as of being $\phi$.

Not only does this deny what I have claimed to be the commonsense understanding of imagination as a representational state, it fails even to allow that understanding to be formulated. The Experiential Hypothesis speaks not of imagining something as being some way, but simply of imagining being some way, and from the inside; if there is a suppressed subject before the participle it can only, given the tenor of Peacocke's discussion, be "oneself". If one accepts the Peacockian theory there is no way in which what I have claimed to find in common sense can be formulated.

It is not necessarily evidence against a theory that it transgresses what one takes to be the bounds of common sense. If a theory's counterintuitiveness was conclusive evidence of its falsity, then we'd all be followers of G. E. Moore. Nevertheless, it is reasonable to object to a theory on these grounds, and such an objection places the burden of proof on the theorist who is flouting our intuitions. This is particularly the case when the theory claims to be built on conceptual truths as the Peacockian theory of experiential imagination does. If these conceptual truths can be contested as contrary to intuition, then clearly the relevant concept is in dispute, and that is what has happened here. To build a theory out of our concepts it is necessary that those concepts are understood correctly, and it seems that the understanding on which the Peacockian theory rests can be challenged. 
This comes out quite clearly when one considers the General Hypothesis, which covers the sensory aspects of all uses of the phenomenologically distinctive state. The General Hypothesis says that to imagine something " is always at least to imagine, from the inside, being in some conscious state". Notice that "imagine" is occurring within the hypothesis, and that all the references to the distinctiveness of the states which the hypothesis covers lie within its scope. In order to understand the general hypothesis, therefore, we must already have a grasp of what imagination, in the wider sense, amounts to. And here's the rub. "Imagination", as most obviously understood, clashes with the use which the Peacockian theory needs to make of it. It will not do the job; a wider conception of imagination is required to understand, and hence make acceptable, the General Hypothesis (and a fortiori the Experiential Hypothesis), and this wider concept undermines the particular use of the concept which the Peacockian theory makes use of.

\section{The Common Sense Concept And The Peacockian Concept}

It seems that the Peacockian theory, if it is to be understood, presupposes possession of a concept of "imagination" which it treats as primitive, and that this concept is incompatible with the specific use which the Peacockian theory requires of it.

Perhaps it would be sensible to try to forestall a possible objection to this line of attack before developing it. I said in chapter two that I was not offering a general account of imagination. I also denied that I was arguing explicitly that experiential imaginmation needs to be understood as a an instance of the wider phenomenon of imagining; the question of the connection between states of experiential imagining and other imaginative states, which might be put as a query about the extent to which the various uses of "imagine" connote the same operation, or a set of states bearing a family resemblance to each other, is supposed to be untouched as an explicit issue in the current treatment. ( I have said that experiential and non-experiential imaginings can occur during the course of the same project. That is not the same as tracing an explicit connection between them, and 
neither was this done by my brief earlier remarks about the differences between labels and ordinary imaginative propositional contents.) Am I now breaking that self-imposed ordinance, and involving the wider issue ?

The answer, I think, is no. I am not going to make an explicit connection, or argue for a definite view about the relation of experiential imagination to the wider state. But in order to evaluate the Peacockian theory it is necessary to reflect on the extent to which one thinks our everyday concept of the imagination can play the role Peacocke wants it to play. My interest in it at this point is thus heuristic only. I am not going to try to provide a sophisticated analysis of that concept, because I think that however sophisticated one's survey of it was, it would have to respect the basic grasp of that concept as it plays a role in our thoughts; and that basic grasp, I contend, shows the Peacockian theory to be mistaken.

Here is the argument. Peacocke acknowledges the different uses of "imagine" and its cognates, and makes it clear that he is not interested in that use of the term which connotes supposition or false supposition (p.20). Rather he is interested only in "imagine" as it refers to a distinctive phenomenal state. But as we have seen, he uses "imagine" in his General Hypothesis, which "is a constitutive claim about what it is to imagine something". (p.21) But obviously Peacocke is not attempting a reductive analysis of imagination, otherwise he would not use it in the General Hypothesis; he treats the states which are his analysanda as a special case of a mental phenomenon already familiar, which is why he can use the term in the analysantia. So what sort of concept is he presupposing his audience's grasp of ? It probably is not supposition in the literal sense, but like S-imagining, it is presumably a case of thinking about something. At least part of our concept of imagination is surely that it is a way of thinking about certain things, often in a novel or extraordinary manner. To imagine is thus to be in an intentional state. But it is not clear what one thinks about in such states. I have claimed that the common sense view, which it behoves philosophers to treat with respect, 
maintains that one typically thinks of the external world as being a certain way, although one's experiences could also be what is thought about. However, according to Peacocke's Hypotheses, it is only oneself (in the attenuated sense covered by the first-person way of thinking ) that one can think about in experiential imagination. This is because one is imagining one of a range of possible experiences, and not one of a range of ways the wider world might possibly be like.

Someone who was wedded to the theory I have developed out of Peacocke's work in this chapter could say at this point "Very well, suppose I accept your contention that imagination is a way of thinking about things. You yourself admit that one's own experiences can be among the things which are thought about. All I need to do is to claim that in sensory cases one's own experiences are always what is thought about. That is part of what makes these states sensory in the first place. That does not support the contention that imagining in the wider sense in which the Peacockian theory requires it to support the Hypotheses threatens the treatment which the Hypotheses provide." This reply supposes that it can draw strength from the fact that in some circumstances one does imagine one's own experiences, and generalises this to cover all cases of experiential imagination. This restates the General Hypothesis, but now with a little more support. However, this cannot be based merely on our concept of experiential imagination; it would surely come as a surprise to most people to be told that in imagining they are thinking about themselves. Put like that, it is surely a very controversial claim, which is not how it is intended by Peacocke. It seems likelier that our concept sees imagining one's own experiences to be a special case of imagining the world as being some way. In such cases, the sensory core is a (type) image which may occur in more usual cases; it is the label which specifies that in this particular instance it is oneself which is being represented. (I argue for this at greater length in the next chapter.)

\section{A Further Objection}


There is a further argument which could be brought against the Peacockian theory. At first glance, it might look like an extension of the previous argument, but in fact it is independent of it. Moreover, it applies to only one way of developing Peacocke's remarks; the developed position is not one which a Peacockian need be committed to. I will first state the objection, and then try to show how one way of developing Peacocke's position evades it.

The argument goes as follows. The Peacockian theory supposes that there is a way of thinking about one's experiences (a way of imagining) which makes those thoughts experiential, and there seems no reason to accept this. After all, if I imagine the leaning tower of Pisa, my thoughts about it do not, in virtue of having that singular content, become tall, lopsided and Italian. So imagining $X$ does not make one's imagining $X$-like. Why then should there be a type of imagining which is experiential, just in virtue of being about an experience?

Now it is clear that one can think about an experience without one's thought being at all experiential. If this is generally the case, then things will be even worse for the Peacockian theory. Not only will there be cause to wonder why thinking about an experience will make it experiential, but there will be counterexamples which can be cited to assert the opposite.

The sense in which there can be non-experiential ways of thinking about an experience is straightforward enough. Suppose I tell somebody that I lurched home from the pub last Friday night with my head spinning and my insides heaving, singing "The Ball of Kirriemuir". It is surely plausible to claim that I am thinking about an experience when I proudly or regretfully relate this shameful episode. Yet there is no obvious reason to suppose that I must employ mental images, or imnagine the sensations or other experiences I actually enjoyed (if that's the word) on that occasion. Equally, I can imagine 
such an experience without any imagery or other sensory aspects occurring in the imaginative episode.

The objection seeks to establish that imagining an experience is not enough to make the imagining experiential. What considerations could be advanced by a Peacockian, to show that experiential imagination is experiential in virtue of being a way of thinking about an experience? The response would be to show that the objection has force only if it is directed against one way in which the theory might be developed, but not another.

The difference in these two ways of developing the theory can be seen by reflecting on the follwing difference. If I believe that I believe that $p$, it is at least questionable whether or not I believe that $p$. Things are different, however, if I entertain the thought that I entertain the thought that $p$. In that case my overall mental state includes the relevant content. (Similarly, one might say that in entertaining the thought that not- $p$ there is a sense in which one entertains the thought that $p$ ). There are certain attitudinive relations which may be borne to a content even if that content is itself a proper part of another content. If the Peacockian understands imagination in this way, as one such relation, then he can claim that in imagining that I see $X$ as $Y$, my mental state includes the nested content of the experience I imagine myself as having.

The second objection, which I have just outlined, works only if the Peacockian theory sees imagination as akin to belief. One could term this a pure representational view; it seems that if imagination simply represents an experience it will not thereby be experiential. If the Peacockian theory is developed along the lines of the response I gave above, as akin to entertaining a thought, then it will become partly an "exemplification" theory. Imagining will inherit experiential properties of some sort, and hence exemplify them in its turn. 


\section{Conclusions}

The second objection can be met if the Peacockian theory can explain how imagining an experience can make that imaginative episode experiential. There remains the problem, however, of the theory's overall counterintuitiveness. This gives us a good reason to at least question the Peacockian theory as a positive account of the connection between experience and the sensory core of experiential imagination, and if an explanation can be found which fits common sense, then that is a better explanation, and the Peacockian theory can be rejected (that is not to say that it does not contain insights that ought to be preserved, only that on this specific point it is in error).

The common sense understanding of experiential imagination is that, like all imagining, it is a way of thinking about the world. In the sorts of imaginings under consideration it is not the case that one's imagining is experiential simply because it represents a possible experience. If a connection with experience is required then it seems that one should look for properties shared by both experience and imagination.

A possible candidate for such a property might trade further on the phenomenal similarity between, for instance, visualising and perceiving. One might think that since there is this qualitative similarity between the two cases, the relevant connection ought to be explained in terms of shared qualities. The basis of such an explanation can be unearthed in a discussion of the qualitative aspect of experience by Hugh Mellor in his paper "Nothing Like Experience". In the next chapter I shall present Mellor's arguments, criticise them, and then go on in the final chapter to suggest that the relevant connection might exist at the level of nonconceptual content. 


\section{MELLOR'S VIEW}

The Problem

Having understood that the sensory core of imagination "as of" is experiential one faces next the problem of explaining how it comes to have this property. In the last chapter I considered an explanation deriving from Peacocke. This view was rejected because it entailed a denial of the apparent common-sense truth that in imagining the world is represented as being some way by the imaginative experience, and put in place of this conception a rival view, which said that in experiential imagination one imagines being in a state of mind. Rather than accept this rival to the more common-sense understanding of imagination, we should look for an understanding of experiential imagination which explains how it represents the world, and what it has in common with perceptual experience.

Experiential imagination represents the world as being some way, and so, I have claimed, does perception (see chapter 2). It seems that the link between the two types of states is not exhausted by this bare functional similarity; the search is on to find something which they have in common. It is natural too to suppose that in this common property lies the explanation of experiential imagination's representational capacities. Accordingly, it will be convenient to find a treatment of the topic which makes this commitment, and to examine its credentials. In this chapter I examine one theory which proposes a candidate for playing the role of what experiential imagination and veridical perception have in common. This suggestion, which is Hugh Mellor's, sees them as having in common the instantiation of relevantly similar qualities; qualities had by experiences of the world do not simply crop up again in experiential imagination, but the latter type of state is realised by mental episodes containing qualities which can be correlated with qualities involved in realisations of the former type, and these qualities are what enable 
us to imagine experiences of the world, and hence to know what they are like. (Mellor, "Nothing Like Experience") I shall criticise Mellor's account on grounds intended to rule out one form of explanation of experiential imagination which is incompatible with Peacocke's proposals. In the succeeding, final, chapter I will try to indicate where the elements of a more acceptable positive proposal might be found.

\section{Mellor; Imagination as Secondary Experience}

Mellor presents a conception of the imagination designed to evade a difficulty which he sees in his conception of how one knows what an experience is. To know what an experience is, says Mellor, is to be able to imagine it correctly. This view derives from the "know-how" response offered by Nemirow and Lewis to Nagel's defence of subjectivity and Jackson's "knowledge argument" for qualia. (The original arguments are in T. Nagel, "What Is It Like To Be A Bat ?" in his Mortal Questions, pp.165-80, and F. Jackson, "Epiphenomenal Qualia", Philosophical Quarterly, vol 32 (1982), pp.127-36; the responses are L. Nemirow, "Physicalism and the Cognitive Role of Acquaintance", in W.Lycan (ed) Mind and Cognition, pp.490-9; D. Lewis, "What Experience Teaches", (ibid.) pp.499-519) This ability to imagine an experience is not entailed by knowing facts about the experience. An exhaustive knowledge of those facts is compatible with complete inability to imagine the actual experience, because knowing facts is knowing that propositions are true, whereas knowing what feeling warm is like is knowing how to imagine feeling warm (p.8) But when one imagines that experience, one's imagining is itself an experience. So how does one know what that second experience is ? Clearly, if a further experience is required to recognise the imaginative experience then the question simply recurs, and one has stepped onto a treadmill of vicious regress.

The regress is only apparent claims Mellor, because whereas seeing red or tasting sugar are "primary experiences", imagining seeing red, or imagining 
that one is tasting sugar, are "secondary experiences". Attempting to imagine such experiences is futile - if one attempts to imagine imagining tasting sugar, one just imagines tasting sugar. The moral Mellor draws is that "we do not know what our secondary experiences are like". (p.12) Experiential imagining is one such secondary experience. Indeed, it is just another name for secondary experiences in Mellor's sense, since he defines a secondary experience as what one has in imagining a primary experience (p.11). Leaving aside the particular role these states play in Mellor's wider design, it is important for my purposes to see how Mellor relates these experiences to his primary experiences, in order to see how they too represent the world, if that is what they do.

There are remarks in Mellor's paper which might lead one to think he understands experiential imagination broadly as Peacocke does, that is, as imagining being in some conscious state; thus, he talks of imagining tasting sugar. In fact, he includes within experiential imagining any imagining which has a phenomenal aspect, including in that imagining of "an external object, like lightning" (p.11) as well as imagining primary experiences. In fact, if we take the latter case to be an instance of imagining oneself as being some way, e.g imagining oneself tasting sugar, or, more broadly, imagining some individual as being some way, then cases of imagining an experience can be included within the analysis of experiential imagination as representing something as being some way. In imagining tasting sugar, I represent the world as being some way - as including me, tasting sugar.

Some harmless gerrymandering thus allows all Mellor's cases to be considered on the same footing, and Mellor himself treats the two states, after he has distinguished them, no differently. (See, for instance, the top of page 12, where a mental image of Westminster Abbey, and imagining "seeing something red, hearing a tune, and tasting sugar" are all treated on a par.) Doubts might arise about the gerrymandered picture in one respect, however. Mellor apparently looks upon episodes of experiential imagination which are about what he calls "external objects" as ways of representing the world. He 
says for example that when " I know what Westminster Abbey looks like, my knowledge is of an objective view of it, of something we could photograph . . . my mental image of Westminster Abbey is an image of it, not of my experience of seeing it" (p.10) This is clearly a ringing rejection of the Peacockian view of experiential imagining as imagining a state of mind. It resonates splendidly with the view I have assumed common-sense to require; experiential imagination, like imagination generally, is a means of representing the world. No doubts need surface here, but where they might press is in considering the extension I have suggested, which sees imagining one of Mellor's "primary experiences", such as tasting sugar, as simply a case of imagining $\mathrm{X}$ as $\mathrm{Y} ; \mathrm{X}$ in this case being oneself.

I think that these doubts can be dispelled; the purely phenomenal aspect of imagining oneself (or someone else) tasting sugar is not discriminably different from imagining the taste of sugar. Similarly with the difference between imagining something red and imagining, from the inside, an experience as of seeing red. The phenomenal aspect in these two cases does not vary across them, any more than the image varies when one images John as fat or when one imagines John as pregnant. This symmetry suggets that the different Mellor cases can be handled as the difference in the cases of imagining John was handled; when I imagine myself tasting sugar, as opposed simply to the tase of sugar, it is the label that fixes the difference - the sensory core of these two different episodes is the same. There is support enough for this in the Mellor; he talks on page 4 of imagining a tune, and does nothing to distinguish this from his treatment of imagining hearing a tune.

So Mellor's picture can be reconciled neatly enough with the general picture I've adopted. The question is now that of deciding how we are to understand the "secondary experiences" Mellor speaks of. Can they deliver a satisfactory explanation of experiential imagining's representational properties, and the link those properties have with perceptual experience? 
Criticisms of Mellor's Account

As I have presented Mellor's theory, it presents the sensory core of experiential imaginative episodes as connected not to experience, but to what an experience is (or could be) an experience of. Since experience is distinctive in having sensory qualities, it seems that sensory qualities must occur in imagination as well if Mellor is right. And here's the rub; the theory hypothesises that imagining being in pain, for instance, involves not imagining an experience of being in pain but having a "secondary experience" of being in pain. The same is true of imainging Westminster Abbey - it entails having a "secondary experience" of Westminster Abbey. Now, if the representational content of veridical experience is fixed by sensations, then if these sensations occur during imagination it becomes hard to see how imagination can be distinguished from veridical perception. If the same sensations show up in imagination as show up in experience, then imagining being in pain becomes indistinguishable from actually being in pain, and the difference between imaging Westminster Abbey and really looking at it collapses. Nobody, I take it, would swallow this consequence. Anyone tempted by it should merely wonder whether she would rather obey a command to imagine being in pain, or to have pain inflicted on her. If the two experiences have sensations in common, then there should be no reason for preferring one to the other. But it is surely apparent that imagining the most intense pain is preferable to having a really rather moderate amount of pain inflicted on one.

Mellor is among those who baulk at accepting the evident absurdity that imagining walking home in the rain is just like walking home in the rain. As he puts it, "I need to go on buying sugar, and my favourite malt whisky, which I would not need to do if imagining their tastes was at all like actually tasting them. " (p.11). Despite Mellor's wish to deny this manifest untruth, it is not clear that he has the resources to make his denial stick. Calling an imaginative experience which entails the ability to recall or otherwise recognise an experience of sipping Glenlivet a "secondary" experience does not show 
what the connection is between sipping Glenlivet and imagining its taste. To say that it is another sort of experience gets one nowhere, for surely that was never in dispute. If it is like a primary experience in virtue of the phenomenal qualities both have in common then the absurdity of the last paragraph forces itself upon us. If it is not like its corresponding primary experience in virtue of these shared sensory qualities, then how is it like them? Mellor's solution is to point out that one cannot imagine a secondary experience, and that since knowing what an experience is like depends on being able to imagine it, we cannot know what our secondary experiences are like.

Even if one accepts this last claim, however, it still seems perfectly possible to ask for a conceptual connection between experiential imagination and perception that could be specified independently of how these two experiences feel. But such an approach is not possible if one thinks that the relevant connection depends on the instantiation of "what its like" qualities. If such an approach is adopted then there seems to be a choice of two options; either one bites the bullet and says that the same qualities are instantiated in both experiential imagination and veridical experience, which seems to be ruled out by simply reflecting on experience, or one simply opts for silence, remarking that we know what the qualities instantiated in experiential imagination do (they partly constitute experiences which enable us to recognise primary experiences), but not what those states are like. But why should we be fixated on what these states are like, though ? A different approach seems possible; one might look for properties, possessed by both experience and sensory imagination, which are not themselves sensory, but nonetheless enable conclusions to be reached about the connection between these two states, and the representational properties of experiential imagination. The need for and possibility of such an approach might be more apparent if some conclusions are drawn from the present discussion. 


\section{Conclusions}

Mellor faces a dilemma. Either he can opt for an explanation of the link between imagination and experience on the basis of shared qualities, or he is unable to explain the link. In the first case, he seems unable to state what sorts of qualities there are which obtain in both primary and secondary experiences. If he opts for common "what it's like" qualities across the two states then he is led to the conclusion from which he shies away, that imagining being in pain and being in pain are indistinguishable states. This difficulty is heightened if one denies Mellor's claim that we do not know what our secondary experiences are like. Such a denial would proceed by accepting that trying to imagine imagining tasting sugar leads only to imagining tasting sugar. But one could then claim on the strength of this that our secondary experience, imagining tasting sugar, is like our experience of tasting sugar. We do know what it's like, it's like tasting sugar, and it is because our secondary experience is like our primary experience that it enables us to know what the latter is like. Mellor wants to deny this, and one can see why, because if "like" is taken in a strong sense it collapses the difference between $X$-ing and imagining $X$-ing; however, if imagining $X$-ing enables us to know what it's like to $X$, then it must surely be like $X$-ing in some respect.

Even if one does not make this objection to Mellor, it seems clear that if a secondary experience is to serve as a means of knowing what a primary experience is like, then there must be some relevant similarity between the two types of experience. Somehow, the one must be reminiscent of the other. Mellor's commitment to the qualitative aspects of experience leads him onto the first horn of the dilemma; the requirement that he explain why a secondary experience is reminiscent of the corresponding primary experience in terms of such qualities.

If Mellor rejects this first horn of the dilemma he must embrace the second horn. In that case, he must accept an account couched not in terms of qualities, but in terms of something else. If he does this it seems that he must 
accept that an appeal to imagination will not do the job that he has demanded of it, and agree that there being something that a secondary experience is like cannot just be a matter of its enabling one to recognise a primary experience.

Mellor's approach does not indicate that it is wrong-headed to reject Peacocke's conception of the link between imagination and experience. Rather, it demonstrates the extreme unwisdom of looking in the wrong place. Specifically, Mellor illustrates the difficulties inherent in trying to keep something sensory in common between the two types of state. Whilst the account derived from Peacocke was rejected for making experiential imagination into imagining a state of mind, Mellor's account should be rejected for making it too much like experience, because of an ill-advised concentration on sensory qualities.

Perhaps these two approaches represent the Scylla and Charybdis a successful theory must sail between. A more fruitful approach might be to endorse the broad approach Mellor takes, but avoid the difficulties of his solution. Such an approach would see imagining as representational, but not in virtue of sensory qualities shared with experience. In the concluding chapter of the thesis, I make some tentative proposals about what the elements of such an account might look like. 


\section{TOWARDS A POSITIVE ACCOUNT}

\section{The Problem Again}

It was argued above that Mellor's proposals suffered from a fixation on trying to explain the phenomenal similarity of sensory imaginative states and veridical experience in terms of shared qualities of the two experiences. On the other hand, the discussion of the Peacockian theory which preceded it found that theory to be unacceptable as well, since, among other worries, it made experiential imagination into a way of imagining a state of mind. It might seem, therefore, that the only viable alternatives have both been found wanting. This is not necessarily the case however; although the arguments which the Peacockian account fell foul of seem to rule out that whole general approach, it may be that the details of Mellor's proposals, rather than its general tenor, are what are unacceptable. After all, I have argued that, like perception, imagination "as of" represents the world as being some way. It seems natural to suppose that there will be something in common between the two states, therefore, that serves to fix content.

\section{Sensations in Common?}

Mellor's account seemed to seek qualities which might be shared by the sensory core and perception. It seems clear that these cannot be sensations, for two reasons. Firstly, if the same sensations were common to the two states, then as remarked above, suffering pain and imagining it would seem to be phenomenally indistinguishable. Secondly, there is a problem if one supposes, as I did in the discussion of Scruton's claims earlier on, that sensations are intentional. This is because it is apparent that if sensations are intentional, then they represent the world as being some way. Now, in imagination one can represent the world as being some way at any time, and in any place; one can 
imagine events which took place a millenium ago, or one can imagine contemporary events occurring at a great distance. On the other hand, sensations represent the world as it is here and now. This is perhaps most evident if one thinks of bodily sensations. A sensation of pain carries information about how it is with me, now. It would be very odd to think that my bodily sensations represent my body as it was some time ago, or in a place other than its location at the time at which the sensations occur. What is true for bodily sensations seems to be true of other sensations also; a sensation of blue represents something (typically a surface of some object, say,) as blue; that thing is represented as currently salient. If this were not the case then we couldn't act on perceptual information. If it did not represent things as they currently are then one would be unable to respond to the environment as one in fact does. If I see something then I know where it is at the moment. If perceptual experience did not represent the here and now, this capacity would be very mysterious.

It cannot be sensations that are the common content-fixing factor in both perception and imagination. If they were the link, then imagination would not be able to range as freely in space and time as it does. At this point one might be tempted to wonder if this counted in favour of the Peacockian theory. That theory, recall, linked experiential imagination to the first-person way of thinking about oneself. It might be urged that this provides a way for sensations to show up in sensory imaginative states; the sensation which occur in such states represent the imagined world as it is, there and then, for the subject of the experience which one is imagining to take place.

I think there are two reasons why this reply is implausible. Firstly, it commits one to the Peacockian theory, and all the undesirable consequences thereof, as detailed in the preceding section. This consideration on its own is not enough to render the Peacockian picture appealing. It does not outweigh the arguments which formerly told against it. More specifically, it is unclear why one should want to save sensations in this way, for think what would 
happen if one could. If sensations were saved the ensuing position would be one in which the experience imagined would have its content fixed in virtue of the sensations which the same type-experience would have in the actual, rather than the imagined world. This would mean that one would have imagined an experience phenomenally indistinguishable from a real experience. This position is even more implausible than Mellor's. Mellor's view got into difficulties by trying to say that imagining Westminster Abbey was, in some elusive respect, phenomenally like seeing Westminster Abbey. The Peacockian view, augmented with sensations, makes imagining Westminster Abbey a state in which one imagines an actual experience. Now, imagining an actual experience is one thing, but the objection, if it were true, would mean that when one imagines an actual experience one enjoys the sensations which occur in such an experience. Once again, the distinction between what it's like to imagine a sensation, and actually having a sensation, seems to collapse. This general point afflicts not just those who believe that sensations are intentional, but also any view that seeks to involve sensations in sensory imagining; if sensations occur when one imagines then imagining something and actually sensing something will be indistinguishable.

The "nowness" of sensations is absent in imagination, and since this is so it provides a further reason for rejecting the occurrence of sensations in imagining. It is true, however, that there is a sense in which imagining $X$ is like sensing $X$; that's why one talks of imagining $X$. A good theory of sensory imagination ought to say what it is about such states which make them like the experiences they are like. If the experiences involve sensations, then some way of accounting for our capacity to be in states which are in some way like sensational states is required.

One proposal which could be made derives from Foster's distinction between realised and conceived qualia (see Foster, The Case For Idealism, ch.6, especially pp.103-105). Foster tries to find an intrinsic difference between images and sensations, given that they can be qualitatively identical in content. 
Having rejected the traditional empiricist explanation in terms of vivacity, he concludes that "the only possible answer is that while, in imaging, qualia are merely (albeit transparently) conceived, in sensing they are, in some way or other, realized." (p.103) Now, Foster thinks of qualia pretty much as they are regarded by traditional sense-datum theories (p.104), but I think his general proposal can be put to use shorn of any particular commitment.

The picture would be as follows. Sensations are realised (perhaps as a physical state of some subject) in experience. In experiential imagination, however, they are conceived. It may be easier, in the case of some sensations, to find an intrinsic difference between sensed sensations and imagined ones. Consider the case of pain again; being in pain and imagining being in pain are not qualitatively indistinguishable in the way Foster takes sensing blue and imaging blue to be. It would be very unlikely that one could successfully generalise from such cases across the whole gamut of sensations, however, on the basis of some possible qualitative difference. (You could try this - perhaps there are some situations in which any given image and its related sensation could be distinguished - but I think it's a mug's game). Foster's suggestion seeks to offer a general way of establishing an intrinsic difference between sensations as they crop up in experience on the one hand, and as they are imagined on the other, (it is thus, perhaps, similar in spirit to Wittgenstein's suggestion that images, unlike experiences, are intrinsically voluntary) and one moreover that makes use of a concept, conceivability, which is akin to the sorts of concept one would expect to see used in a general account of imagination, and hence does not threaten to make experiential imagination irreconcilable with a wider theory.

Explaining the phenomenal similarity between experiential imagination and actual experience in terms of the difference between conceived and realised sensations does not tell us what the two states have in common, however. If such is sought, another aspect of experience must bear the weight. 


\section{Nonconceptual Content}

Naomi Eilan has recently suggested that the content of images (and, indeed, of pictures generally) might be distinguishable from the content of sentences "by appeal to the kind of non-conceptual content that might be ascribed to perceptual experiences". (Eilan, "Critical Notice of M. Tye: The Imagery Debate", Philosophical Books, July 1993, pp. 137-143, at p.141). If the content presented by images can be distinguished from that of sentences via non-conceptual content, then images must have such content. In that case, perhaps such content is what images have in common with perceptual exrperiences. To see if this is feasible one would need to be clear about what non-conceptual content is, and then try to use it to solve the problem.

Peacocke's work provides the clearest statements of what non-conceptual content should be taken to be. Peacocke argues that there are many types of content involved in a particular experience; as he puts it, "[t]he representational content of experience is a many-splendored thing" ( $A$ Study of Concepts, p. 61). One type of nonconceptual content is what Peacocke terms a scenario. A scenario can be specified in two steps. First one fixes an origin, which is given by a property, such as being the centre of the chest of a human body, which can be instantiated at many different places in the real world. In this case, the appropriate axes would be "given by the directions back/front, left/right, and up/down with respect to that centre." (ibid. p.62) Second, one proceeds to specify "a way of filling out the space around the origin"(p.63) In doing this, one determines more fully the relevant spatial type. There are complications which I shall ignore here; the important point is that in filling out the space it is not necessary to use a conceptual repertoire possessed by the subject of the experience. It is in this sense that scenario content is nonconceptual; the specification is not constrained by the concepts possessed by the individual whose experience is specified at the scenario level. Another way Peacocke detects for a content to be nonconceptual trades on a suggestion of David Kaplan's to do with the remarkable fine-grainedness of experience. A belief may have the form "that is $\phi$, or "the $\theta$ was $\phi "$, where $\phi$ stands not for 
a concept but for an image or some other impression or idea; "the senses of words are not adequate to giving the contents of attitudes". (Peacocke, "Perceptual Content", in Almog et al. (edd) Themes From Kaplan, pp.297-329, at p.297. The relevant Kaplan is "Quantifying In", in L.Linsky (ed) Reference and Modality, pp.112-144).

So nonconceptual content is that aspect, or those aspects, of content which is not specifiable, or need not be specified, using concepts possessed by the subject of the experience. (For other discussions of nonconceptual content, see G. Evans, The Varieties of Reference, esp. ch 5.2 \& pp.157-9 \& 226-229. Also relevant is Dretske, Knowledge and the Flow of Information, esp. Part 1)

Now, Eilan's insight was to see that even if one adopts a purely representational view of imagery, a sensitivity to nonconceptual content allows one to argue that "it is still the case that there are aspects of the phenomenology that should be appealed to in explaining the sense in which imaging is like perceiving, and also the sense in which imaging is like picturing." (Eilan, op.cit, pp.141-2). In other words, this approach may enable us to steer a middle course between the approaches of Peacocke and Mellor. If one adopts the general approach presupposed by the Peacockian theory (I prescind here from the complications mentioned at the end of chapter 5), one is left with experiential imagination as imagining a state of mind. It seems that this runs counter to our intuitions, for surely what we take ourselves to be doing in imagination is thinking about the objects in the imagined world, and not about ourselves, or some other subject. On the other hand, an attempt to cash out what the connection between perception and experiential imagination is in terms of qualities runs into the difficulties faced by Mellor's treatment; it either seems to make the two states indistinguishable, or it is unable to articulate the connection whilst keeping them distinct. Yet there seems to be something right about the sort of approach Mellor takes. Accounting for the connection between these states without mentioning their phenomenal similarity seems to miss something important. (Note also that if Peacocke's 
account is cashed out as an "exemplification" theory, as I suggested could be done earlier, (see p.68) it will become a variety of this view, since it too cuold admit of an appeal to nonconceptual content.) Eilan's suggestion has this merit; one might wish to dispense with qualia (and hence the need to follow Foster's approach) altogether, by reducing qualia to representational properties, and arguing that these are the only properties which the sensory core of imagination "as of" possesses. At the same time, one might want to preserve the intuition that notice must be taken of the phenomenological similarity; this would be done by explaining the similarity that these states bear to each other, and to picturing, by appeal to nonconceptual representational contents.

As it stands, Eilan's suggestion is no more than a suggestion, and this line of approach needs much more work. As things stand, however, it seems the best candidate for playing the role of an explanation which avoids the general problem and preserves enough of our intuitive understanding of the imagination. My main concern has been to set out that problem, of how the link between imagination and experience is to be explained, but I should not like to conclude without suggesting that nonconceptual content may turn out to be at least part of the solution. 


\section{CONCLUSION}

Let me sum up the main points of what has gone before. In this thesis I have claimed that experiential imagination represents the world as being some way, just like imagination, and indeed thought, generally. It has seemed also that there are good reasons for holding that experiential imagination is Janus-faced; blended from thought and experience (although not all of Scruton's putative quartet serve to establish that imagination is like thought as well as sensation). Worries that these two commitments might be incompatible should be dispelled; one might argue either that experiential imagination instantiates sensational properties, or that sensations are reducible to sensational properties. Now, I argued in chapter 7 against the idea that sensations could be realised in experiential imagination, and said that even if one thought of them as conceived, that would not tell us what made experiential imagination experiential.

To try to answer that question, two main approaches were reviewed, on the back of a general argument for the conclusion that imagination as of the world being some way is divided into a sensory core and an accompanying propositional label. The first approach considered was Peacocke's, which saw experiential imagination as imagining experiences. I argued that this position could be developed so as to make it an "exemplification" view, rather than a purely representational one; that would explain how the sensory core of imagining "as of" is experiential. It does not, however, evade the other main objection which I made against this general approach, which is that it is counterintuitive in the extreme, disputing the commonsense view that in imagination one thinks about the world - the objects and properties that one experiences - and not about oneself.

The other main approach I looked at was Mellor's, and I argued that it suffered from a fixation on qualities as the locus of explanation. I argued that 
to focus on qualitative aspects of experience as providing the connection between experience and experiential imagination was to look in the wrong place. The specific criticism was that there seemed no way on this view to account for the difference, rather than the resemblance, between experience and sensory imagination. Although this approach respects our intuitions, it is unable, if cashed out in terms of qualitative aspects, to provide a satisfactory solution.

So I argued that a middle course would be necessary, and suggested that Eilan's insight should be explored further. That insight was that nonconceptual content would allow a solution which respected the apparent need to mention the phenomenal similarity between experiential imagination and experience of the actual world, whilst at the same time it avoided becoming hamstrung by a concern with qualities. Indeed, such an approach would allow for a reduction of qualia to intentional properties, whilst still permitting us to respect the claims of phenomenology. Although much work remains to be done, it seems that one might make a tentative suggestion that an examination of nonconceptual content might be a step towrds a solution of the difficulties which I found in the approaches which I reviewed. 


\section{BIBLIOGRAPHY}

D.M.Armstrong; A Materialist Theory of the Mind, London, Routledge 1968

G. Berkeley; Philosophical Works, ed. M. Ayers London, Dent 1975

N. Block (ed.); Imagery, Cambridge, Mass. MIT Press, 1981

M. Budd; Wittgenstein's Philosophy of Psychology, London, Routledge 1989

- ;"How Pictures Look", Inaugural Lecture, University College London, 1991

F. Dretske; Knowledge and The Flow of Information, Oxford, Basil Blackwell 1981

M. Dummett; Frege; Philosoophy of Language, 2nd ed. London, Duckworth 1981

N. Eilan; "Critical Notice of M. Tye,'The Imagery Debate"', Philosophical Books, July 1993

G. Evans; The Varieties of Reference, Oxford, Oxford University Press 1982

J. Fodor; The Language of Thought, New York, Crowell 1975

J. Foster; The Case For Idealism, London, Routledge, 1982 ;; A.J. Ayer, London, Routledge 1985

N. Goodman; Languages of Art, Indianopolis, Bobbs-Merrill, 1968

D. Kaplan; "Quantifying In", in L.Linsky (ed.), Reference and Modality, Oxford, Oxford University Press, 1971

F. Jackson; "Epiphenomenal Qualia", Philosophical Quarterly, vol.32, 1982

W. James; The Principles of Psychology, Cambridge, Mass. Harvard University Press, 1983

D. Lewis; "What Experience Teaches", in W. Lycan (ed) Mind And Cognition, Oxford, Basil Blackwell 1990

D.H. Mellor; "Nothing Like Experience", Proceedings of the Aristotelian Society, vol. XCIII, pt.1, 1992-3

T. Nagel; "What Is It Like To Be A Bat ?" in Mortal Questions, Cambridge, Cambridge University Press, 1979

L. Nemirow; "Physicalism and the Cognitive Role of Acquaintance", in W. Lycan (ed) Mind and Cognition, Oxford, Basil Blackwell, 1990 
C. Peacocke; "Wittgenstein \& Experience", The Philosophical Quarterly, vol.32, 1982

;; Sense \& Content, Oxford, Clarendon Press, 1983

-; "Imagination, Experience \& Possibility", in J. Foster \&

H. Robinson (eds.) Essays on Berkeley, Oxford, Clarendon Press, 1985

;; "Depiction", Philosophical Review, vol 96, 1987

-;"Perceptual Content", in J. Almog, J. Perry \& H. Wettstein (eds.),

Themes From Kaplan, New York, Oxford University Press, 1989

-;A Study of Concepts, Cambridge, Mass, MIT Press, 1993

C.S. Peirce; "Logic As Semiotic; The Theory of Signs," in J.Buchler

(ed.) Philosophical Writings of Peirce, New York, Dover 1955

G. Pitcher; $A$ Theory of Perception, Princeton, Princeton University

Press, 1971

;; Berkeley, London, Routledge 1977

R. Scruton; Art and Imagination, London, Routledge 1982

A. D. Smith; "Berkeley's Central Argument" in J. Foster \& H. Robinson (eds) Essays on Berkeley, Oxford, Clarendon Press 1985

P.F. Strawson; "Imagination \& Perception", in. L. Foster \& J.W. Swanson

(eds.) Experience and Theory, London, Duckworth 1970

M. Tye; The Imagery Debate, Cambridge, Mass. \& London, MIT Press, 1991

K. Walton; Mimesis As Make-Believe, Cambridge Mass. Harvard University

Press 1990

M. Warnock; Imagination, London, Faber \& Faber 1976

G. Watson; Phantasia in Classical Thought, Galway, Irish University

Press, 1990

L. Wittgenstein; Philosophical Investigations, 3rd ed, G.E.M. Anscombe

(tr.), G.E.M. Anscombe \& R. Rhees (eds.), Oxford, Basil Blackwell 1967

-; The Blue and Brown Books, 2nd ed. Oxford, Basil Blackwell, 1969

-; Remarks on the Philosophy of Psychology, vol.I, G.E.M. Anscombe

(tr), G.E.M. Anscombe \& G.H. von Wright (eds.); vol.I, C.G.

Luckhardt \& M.A.E. Aue (trs), G.H. von Wright \& H.Nyman (eds), 
Oxford, Basil Blackwell, 1980.

S. Yablo; "Is Conceivability A Guide To Possibility ?", Philosophy and Phenomenological Research, vol. LIII, 1993 